\title{
Labor Mismatch in the Great Recession: A Review of Indexes Using Recent U.S. Data
}

\author{
Maria E. Canon, Mingyu Chen, and Elise A. Marifian
}

\begin{abstract}
Labor mismatch, also known as structural imbalance, can be defined as a poor match between the characteristics of unemployed workers and those required for vacant jobs. In the wake of the jobless recovery from the Great Recession, economists have sought to explain the coexistence of a high unemployment rate and increasing job openings as a mismatch phenomenon. This article reviews five studies that have contributed to the development of mismatch indexes and computes the corresponding indexes over the period May 2005-May 2012 using job vacancy data from the Conference Board Help Wanted OnLine ${ }^{\circledast}$ (HWOL) Data Series. For most of the indexes, mismatch increased during the Great Recession, although the indexes exhibit a range of behaviors. According to an index developed in Jackman and Roper (1987), mismatch can account for at most 2.72 percentage points of the 5.30-percentage-point increase in the unemployment rate from the beginning of the recession to the unemployment rate peak. (JEL E24, J01, J23, J63, J64)
\end{abstract}

Federal Reserve Bank of St. Louis Review, May/June 2013, 95(3), pp. 237-71.

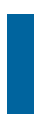

$\mathrm{n}$ the years following the Great Recession, high unemployment rates persisted across the United States despite the steady increase in job openings. $\frac{1}{}$ This unexplained dynamic has led many to believe that the U.S. labor market's slow and jobless recovery could be explained as a mismatch phenomenon. ${ }^{2}$ For instance, supporters of the sectoral mismatch hypothesis have pointed to changes in the employment and vacancy breakdown by sector. From December 2007 to February 2011, more than 50 percent of job losses occurred in the manufacturing and construction sectors, while over 90 percent of new positions opened in other sectors, suggesting that sectoral mismatch may have increased.

Proponents of geographic mismatch—characterized by job vacancies in places different from those where people are looking for work-believe that the slow labor market recovery is rooted in the real estate bust and the subsequent extreme declines in housing prices, which may have reduced the mobility of homeowners. For example, Ferreira, Gyourko, and Joseph (2010)

Maria E. Canon is an economist, Elise A. Marifian is a research associate, and Mingyu Chen is a former research associate at the Federal Reserve Bank of St. Louis. The authors thank Jeanne Shu from the Conference Board for her thorough assistance with the Conference Board Help Wanted OnLine ${ }^{\circledR}$ Data Series. The authors also thank two referees and Andrew B. Langan for their valuable comments.

( ) 2013, The Federal Reserve Bank of St. Louis. The views expressed in this article are those of the author(s) and do not necessarily reflect the views of the Federal Reserve System, the Board of Governors, or the regional Federal Reserve Banks. Articles may be reprinted, reproduced, published, distributed, displayed, and transmitted in their entirety if copyright notice, author name(s), and full citation are included. Abstracts, synopses, and other derivative works may be made only with prior written permission of the Federal Reserve Bank of St. Louis. 


\section{Canon, Chen, Marifian}

conclude that unemployed workers who owe more than their homes are worth would be less likely to apply for and accept positions that require them to sell their homes. $\underline{3}$ Yet Şahin et al. (2012) argue that geographic mismatch has played an insignificant role.

Whether mismatch has caused a significant increase in the unemployment rate is debated among economists and policymakers. In this article, we present a comprehensive review of five studies that have contributed to the historical development of mismatch indexes. For each index, we describe the theoretical framework, interpretation, and links to other indexes. We then compute the described mismatch indexes using (i) Conference Board Help Wanted OnLine ${ }^{\circledR}$ (HWOL) data, which provide information on online job advertisements nationwide by detailed occupations and industries, and (ii) Current Population Survey (CPS) data on unemployment and employment. Our analysis of the indexes includes comparisons within a given index's different types (here industrial and occupational mismatch) and disaggregations, as well as comparisons among the different indexes. We also separate the analysis into three time periods: pre-recession (May 2005-November 2007), Great Recession (December 2007-June 2009), and post-recession (July 2009-May 2012).

We find that the level of mismatch can vary significantly among indexes and within an index's different types and disaggregations. The choice of an index ultimately depends on the question that one seeks to answer, as well as the extent to which one desires a practical interpretation and application of the index. With these points in mind, we believe that one index in particular, developed by Jackman and Roper (JR, 1987) and recently extended by Şahin et al. (2012), stands out as the most practical and intuitive measure of mismatch. What this index suggests is that industrial and occupational mismatch can account for at most 2.72 percentage points of the 5.30-percentage-point increase in the unemployment rate from the beginning of the recession to the unemployment rate peak.

\section{MEASURES OF MISMATCH}

Shortly after the development of the Beveridge curve, $\underline{4}$ economists became interested in the role of mismatch in the labor market. With persistently high unemployment in Europe during in the 1970s and 1980s, researchers began examining nontemporary imbalances between supply and demand for labor across industries, skill groups, regions, and age groups. $\frac{5}{\text { Over the past }}$ three decades, economists have developed various mismatch indexes to measure the level of sectoral imbalance in labor markets and the contribution of this imbalance to unemployment. In this section, we chronologically review eight mismatch indexes, providing the historical context that motivated the development of the index and summarizing the derivation.

Seeking to explain the high unemployment rates observed in the 1970s, Lilien (1982) points to volatility in employment demand over the period. He first notes that the composition of industry employment shares changed dramatically from 1969 to 1980: Manufacturing's share shrank 22.8 percent while the shares of retail trade; fire, insurance and real estate; and service industries grew a combined 47.6 percent. He then observes that (i) employment shocks to durable manufacturing employment coincided with the decade's so-called cyclical increases in unemployment and (ii) the durable manufacturing employment share did not increase significantly 
even when unemployment abated. $\underline{6}$ Given these two observations in the data, Lilien challenges what was then a common belief: That cyclical unemployment represents a deviation from a stable natural rate. He argues instead that most postwar-era unemployment is more accurately described as stemming from workers' attachment to sectors. He argues that this attachmentperhaps the result of wage premiums and industry-specific skills - reduces workers' willingness to look for the available positions in other sectors. As a result, when exogenous shocks create new patterns of sectoral demand, labor markets are slow to adjust and unemployment tends to be high during the transition.

To support his argument that labor's slow adjustment to sectoral employment demand shifts is the underlying source of the decade's high unemployment, Lilien (1982) develops an index to estimate the "dispersion of employment demand conditions throughout the labor market" or

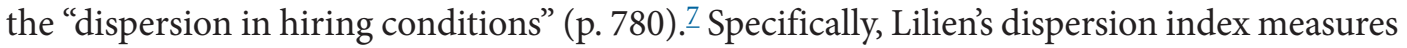
the sectoral employment share-weighted percent log deviations of sectoral employment from total employment, taking the following form:

$$
I_{\text {Lilien }}=\hat{\sigma}_{t}=\left[\sum_{i=1}^{n} \frac{x_{i t}}{X_{t}}\left(\Delta \log x_{i t}-\Delta \log X_{t}\right)^{2}\right]^{1 / 2},
$$

where $x_{i t}$ is the number of people employed in sector $i$ at time $t$ and $X_{t}$ is the total employment for all sectors. Of note, this index has been critiqued for its correlation with both sectoral shifts and aggregate demand fluctuations (see Abraham and Katz, 1986; Neelin, 1987; and Blanchard and Diamond, 1989).

Jackman and Roper (1987) produce the first study that formalizes the notion of mismatch, or "structural imbalance," $\underline{-}$ which they define as a situation in which the characteristics of unemployed workers, such as skill, experience, or location, differ from those required for the vacant jobs. Structural imbalance between the pattern of labor supplied and demanded yields excess unemployment, which they call "structural unemployment." More precisely, they specify that structural unemployment exists when, given the configuration of vacancies, it would be possible to reduce unemployment (increase the job hiring rate) by moving an unemployed worker from one sector to another.

Jackman and Roper (1987) use a static matching model with an unemployment/vacancy framework to develop a measure of structural unemployment, from which they derive various indexes of structural imbalance. ${ }^{9}$ In the context of their model, they define an absence of structural unemployment as the configuration of the existing stock of unemployment that maximizes aggregate hires, given the distribution of vacancies. Their maximization of aggregate hires implies that the unemployment-to-vacancies ratio is identical across sectors when the labor market is at structural balance. Structural unemployment $(S U)$ is denoted by

$$
S U=\frac{1}{2} U \sum_{i}\left|\hat{u}_{i}-\hat{v}_{i}\right|
$$

where $U$ is the total stock of unemployed workers and $\hat{u}_{i}$ and $\hat{v}_{i}$ are sector $i$ 's share of the total stock of unemployed workers and vacancies, respectively. From there, Jackman and Roper's first two mismatch indexes can be derived by normalizing $S U$ on total unemployment (JR index 1, 


\section{Canon, Chen, Marifian}

$J R 1$ ) or on the total labor force (JR index 2, JR2). JR1 measures the proportion of the unemployed in the wrong sector $\underline{10}$ and is denoted by

$$
I_{J R 1}=S U / U=\frac{1}{2} \sum_{i}\left|\hat{u}_{i}-\hat{v}_{i}\right| .
$$

$J R 2$ measures the proportion of the labor force in the wrong sector. It is denoted by

$$
I_{J R 2}=S U / L=\frac{1}{2} \frac{U}{L} \sum_{i}\left|\hat{u}_{i}-\hat{v}_{i}\right|
$$

where $L$ is the size of the labor force.

Jackman and Roper (1987) note that one disadvantage of these two indexes is that they do not indicate how much of the current unemployment is due to mismatch (or, alternatively, how much unemployment would fall if structural balance were achieved). To answer this question, they develop a third index (JR3), assuming that the hiring function is Cobb-Douglas. 11 They use an elasticity of substitution term $\alpha=0.5$, which is within the 0.5 to 0.7 range of estimates used in the literature (Petrongolo and Pissarides, 2001). For this index, they define the levels of unemployment and vacancies at structural balance $\left(U^{*}\right.$ and $\left.V^{*}\right)$ as the levels needed (i) to produce the current level of aggregate hires (which is given) and (ii) to equalize the unemployment and vacancy shares across sectors $\left(\hat{u}_{i}=\hat{v}_{i}\right.$, for every $\left.i\right) . \frac{12}{2}$ Their third index is denoted by

$$
I_{J R 3}=1-\sum_{i}\left(\hat{u}_{i} \hat{v}_{i}\right)^{1 / 2}
$$

and measures the proportion of the observed unemployment attributable to structural imbalance. $I_{J R 1}, I_{J R 2}$, and $I_{J R 3}$ are invariant to aggregate demand shocks that keep $\hat{u}_{t}$ and $\hat{v}_{t}$ constant.

Under a non-accelerating inflation rate of unemployment environment, Jackman, Layard, and Savouri (JLS, 2008) develop a framework in which the optimal unemployment rate is obtained when unemployment rates are equalized across sectors. In the current context, the authors define mismatch unemployment as the distance between the observed unemployment rate and the equilibrium rate. The derivation of their mismatch index relies on the critical assumptions for Cobb-Douglas production functions and double logarithmic wage functions of the form $\log w_{i}=\beta_{i}-\gamma \log u_{i}$. The index, which measures the proportional excess of actual unemployment over minimum unemployment, is defined as

$$
I_{J L S}=\frac{1}{2} \operatorname{var}\left(\frac{u_{i}}{u}\right)=\log u-\log u_{\min },
$$

where $u_{i}$ is the unemployment rate in sector $i$ and $u$ is the mean of the sector-specific unemployment rates (see Jackman, Layard, and Savouri, 2008). The index is a measure of the dispersion of relative unemployment rates $\left(\operatorname{var} u_{i} / u\right)$ across sectors.

Motivated by the high levels of European unemployment in the 1980s and the shift in the U.K. Beveridge curve from 1963 to 1984, Evans (1993) examines the extent to which mismatchwhich he calls "sectoral imbalance"-may have contributed to increased unemployment rates in the United Kingdom. Based on a framework with temporarily inflexible wages, Evans constructs a measure of sectoral imbalance that calculates the average deviation of the percentage difference 
between the supply and demand for labor across sectors (p. 442). This measure is approximated by

$$
I_{\text {Evans }}=\frac{1}{2} \sum_{i} l_{i}\left|\left(u_{i}-v_{i}\right)-(u-v)\right|,
$$

where $l_{i}$ is the sector $i$ 's share of labor force; $u_{i}$ and $v_{i}$ are the unemployment and vacancy rates in sector $i$, respectively; and $u$ and $v$ are the aggregate rates. Evans notes that his index measures imbalance as a share of the sectoral labor forces. Accordingly, he states that unlike many other indexes, his index has the advantage of being invariant to a neutral change in aggregate demand for labor (i.e., the demand for labor in each sector changes by the same percentage). $\frac{13}{}$ In addition, he argues that his index, unlike Lilien's (1982), measures the overall state of labor market imbalance and the contribution of the shocks to the state of imbalance.

Evans's (1993) index is similar to the JR2 index (Jackman and Roper, 1987) in that both attempt to measure sectoral imbalance as a proportion of the labor force. Yet the two diverge in their definition of structural balance: For their second index, Jackman and Roper define structural balance in terms of equalizing the ratio of unemployment to vacancies across sectors, while Evans defines sectoral balance in terms of equalizing the absolute differences between sectoral and aggregate unemployment rate deviations from the sectoral and aggregate vacancy rates. Jackman and Roper state that, given their hiring function assumptions, the definition of structural balance suggested by Evans's index $\underline{14}$ does not maximize the outflow from unemployment (and thus, aggregate hires). They also suggest that the definition in terms of ratios (i.e., the number of unemployed per vacancy) is more natural than one in terms of absolute differences between the unemployment rate and the vacancy rate within a sector.

Most recently, Şahin et al. (SSTV, 2012) approach the mismatch topic motivated by the persistently high unemployment in the United States. Noting that the flow into unemployment has decreased to pre-recession levels, they argue that any theory to explain the recent dynamics in the labor market must explain the long-lasting decline in the rate at which workers find jobs. They hypothesize that sectoral mismatch between available jobs and unemployed workers could explain this lower aggregate job-finding rate. Building on the work of Jackman and Roper (1987), Şahin et al. (2012) develop a dynamic stochastic environment that allows heterogeneity in sectoral matching and productivity efficiencies in the generalized model.

In Şahin et al.s (2012) framework, the optimal allocation of unemployed workers is one that would be chosen by a planner who can move unemployed workers across sectors freely, subject only to the restrictions imposed by matching frictions within each labor market (sector). $\underline{15}$ In their benchmark environment, the solution to the planner's problem states that the planner allocates more unemployed workers to search in the markets with higher vacancies and matching efficiencies. The optimal allocation of unemployed workers across sectors is achieved when the matching efficiency-weighted vacancy-to-unemployment ratios are equalized across sectors. From the planner's allocation rule, they derive their benchmark mismatch index, with the additional assumption that the matching function is Cobb-Douglas. The benchmark index $\left(M_{\phi t}\right)$ is denoted by 


$$
I_{S S T V 1 \phi}=M_{\phi t}=1-\frac{h_{t}}{h_{t}^{*}}=1-\sum_{i=1}^{I}\left(\frac{\phi_{i t}}{\bar{\phi}_{t}}\right)\left(\frac{v_{i t}}{v_{t}}\right)^{\alpha}\left(\frac{u_{i t}}{u_{t}}\right)^{1-\alpha}, \underline{16}
$$

where $v_{i t}$ and $u_{i t}$ are the vacancies and unemployment in sector $i$ at time $t ; v_{t}$ and $u_{t}$ are the aggregate levels of vacancies and unemployment at time $t$; $\phi_{i t}$ is the matching efficiency component for sector $i$ at time $t ; \phi_{t}$ is the aggregate matching efficiency component; and $\alpha$ is the elasticity of substitution. ${ }^{17} I_{S S T V 1 \phi}$ measures the fraction of hires in period $t$ that are lost as a result of misallocation, $1-\frac{h_{t}}{h_{t}^{*}}$, where $h_{t}^{*}$ is the planner's hires and $h_{t}$ is the observed level of aggregate hires.

In the absence of heterogeneities other than vacancies (i.e., matching efficiency, productivity, and job destruction rates), Şahin et al. (2012) refer to the index as $M_{t}$. Specifically,

$$
I_{S S T V 1}=M_{t}=1-\sum_{i=1}^{I}\left(\frac{v_{i t}}{v_{t}}\right)^{\alpha}\left(\frac{u_{i t}}{u_{t}}\right)^{1-\alpha} .
$$

Şahin et al.'s first index $\left(I_{S S T V 1}\right)$ is mathematically equivalent to Jackman and Roper's third index $\left(I_{J R 3}\right)$ when the elasticity term $\alpha=0.5$. It is important to note, however, that $I_{J R 3}$ and $I_{S S T V 1}$ are interpreted differently. When interpreting $I_{J R 3}$, Jackman and Roper (1987) define aggregate unemployment without mismatch $U^{*}$ as the level of unemployment needed to equalize the unemployment and vacancy shares in each sector, assuming a given aggregate level of hires and a given aggregate ratio of unemployment to vacancies. It follows that $I_{J R 3}$ is given by the amount of unemployment (in the aggregate) that exceeds the level that would exist at structural balance $\left(U-U^{*}\right)$ as a share of actual aggregate unemployment $U$ (see Jackman and Roper, p. 14). Alternatively, $I_{S S T V 1}$ is given by the difference between the number of hires that would result from a planner who could freely move workers across sectors $\left(h_{t}^{*}\right)$ and the observed level of hires $h_{t}$, normalized by $h_{t}^{*}$.

Şahin et al. (2012) mention three useful properties of their index: (i) It allows easy interpretation from 0 to 1 , where 0 indicates no mismatch and 1 indicates maximum mismatch. (ii) It is invariant to aggregate shocks that raise or lower the aggregate number of vacancies and unemployed while leaving these shares unchanged across markets. And (iii) it is increasing in the level of disaggregation, which implies that statements regarding the role of mismatch should be qualified with respect to the degree of sectoral disaggregation that is used.

Although we do not provide a full review or computation of it in this article, it is worth noting that Şahin et al. (2012) also construct a second index $\left(I_{\text {SSTV2 }}\right)$ in which they abandon the assumption that productivities and job destruction rates are identical across sectors. This change yields their generalized model, where sector heterogeneity exists in the matching efficiency, vacancy, productivity, and destruction rate components. This second index measures the fraction of hires lost because of job-seeker misallocation at time $t$ and is denoted by

$$
I_{\text {SSTV } 2}=M_{x t}=1-\sum_{i=1}^{I}\left(\frac{\phi_{i}}{\bar{\phi}_{t}^{x}}\right)\left(\frac{v_{i t}}{v_{t}}\right)^{\alpha}\left(\frac{u_{i t}}{u_{t}}\right)^{1-\alpha},
$$


where $\bar{\phi}_{t}^{x}=\sum_{i=1}^{I} \phi_{i t}\left(\frac{x_{i t}}{\bar{x}_{t}}\right)^{\frac{1-\alpha}{\alpha}}\left(\frac{v_{i t}}{v_{t}}\right)$ with $\bar{x}_{t}=\left[\sum_{i=1}^{I} x_{i t}^{\frac{1}{\alpha}}\left(\frac{v_{i t}}{v_{t}}\right)\right]^{\alpha} \underline{18}$ and $\bar{\phi}_{t}^{x}$ is an aggregator of the vacancy share-weighted market-level efficiencies.

Lastly, Şahin et al. (2012) attempt to quantify the contribution of mismatch unemployment to the aggregate unemployment rate. They construct a counterfactual unemployment rate $u^{*}$ that would exist if there were no mismatch:

$$
u_{t+1}^{*}=s_{t}+\left(1-s_{t}-f_{t}^{*}\right) u_{t}^{*},
$$

where $s_{t}$ is the separation rate and $f_{t}^{*}$ is the job-finding rate in the absence of mismatch:

$$
f_{t}^{*}=\frac{f_{t}}{\left(1-I_{S S T V 2}\right)}\left(\frac{u_{t}}{u_{t}^{*}}\right)^{\alpha}
$$

where $f_{t}=h_{t} / u_{t}$ is the observed job-finding rate.

\section{DATA}

We need detailed information on employment, unemployment, and vacancies to compute the mismatch indexes. For employment and unemployment data, we use the Bureau of Labor Statistics' (BLS) Current Population Survey (CPS) estimates for national- and state-level employment and unemployment counts. $\underline{19}$ Our computations of the mismatch indexes use the counts of unemployed and employed workers by industries or occupations, and we seasonally adjust the data. $\underline{20}$ For vacancy counts, we use the Help Wanted OnLine Data Series (HWOL) published by the Conference Board, which we also seasonally adjust. The HWOL provides monthly measures of new and total $\underline{21}$ online job advertisements at various geographic levels for the entire United States. It also provides occupational and industrial classification for the job posts.

\section{Current Population Survey Data}

The CPS is a monthly survey of approximately 60,000 households that began in 1940. In addition to other data, the CPS provides detailed U.S. labor market statistics on employment, unemployment, earnings, labor force participation rates, and those not in the labor force. The CPS estimates are available by demographic characteristics, industry, and occupation. The monthly survey is conducted during the calendar week including the 19th day of the month, and questions are asked regarding the respondent's labor market activity during the previous calendar week (which included the 12th day of the month) - the reference week.

As noted, for the mismatch indexes we use the count of unemployed workers by industries or occupations. Using these data requires the assumption that unemployed workers are searching for jobs in the same sector as their previous job. Şahin et al. (2012) attempt to improve the accuracy of the count by following a method used by Hobijn (2012) that merges monthly CPS data to identify the sectors of the new jobs found by the previously unemployed workers. Şahin et al. 


\section{Figure 1}

HWOL Job Vacancies Data Comparison: U.S. Total Versus National Industry and Occupation Aggregations (May 2005-May 2012)

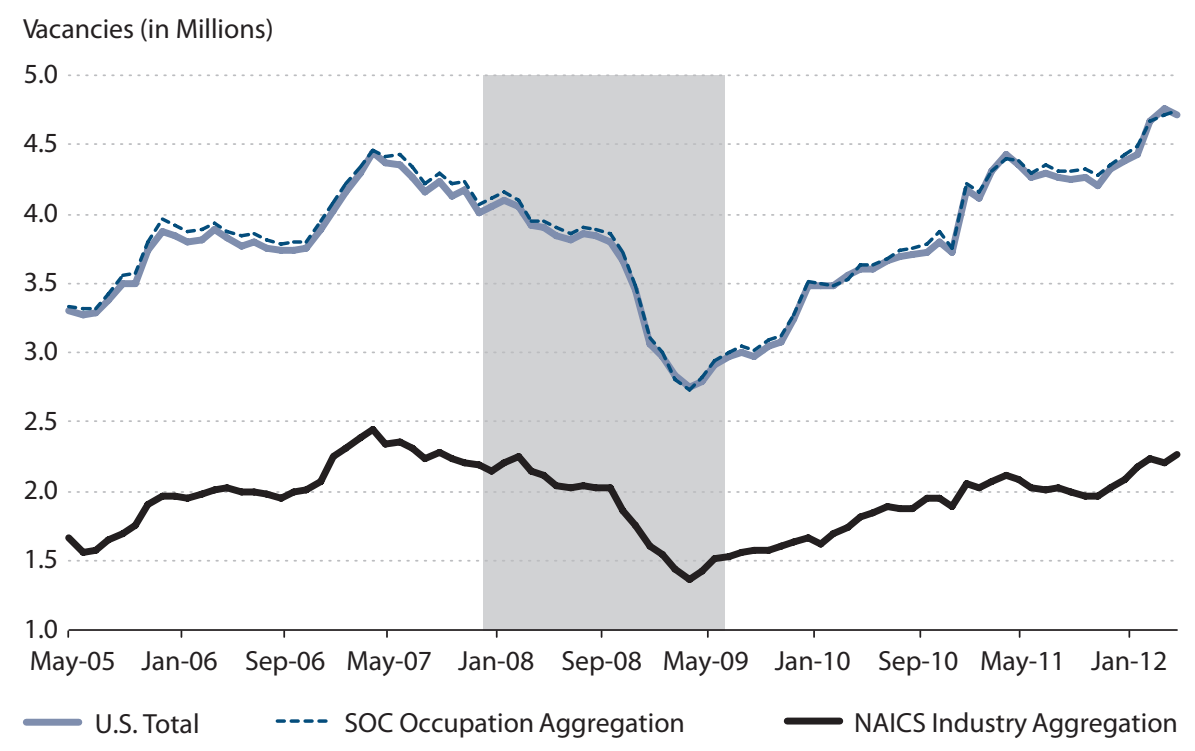

NOTE: The shaded area indicates the most recent recession as determined by the National Bureau of Economic Research. SOC, Standard Occupational Classification system.

(2012) show that this method is sufficient to infer the sectors in which unemployed workers were searching. Nevertheless, an unemployed worker could have past work experience in various sectors (i.e., he or she holds many sector-specific skills) and thus could look for jobs in many sectors, which would not be reflected in the CPS. Allocating this group of unemployed workers to the "wrong" sectors could overestimate the sector-specific mismatch indexes.

\section{HWOL Vacancy Data른}

The HWOL is designed to provide monthly measures of labor demand as determined by advertised vacancies and is targeted to cover the entire universe of online job postings for the United States. Each month's HWOL data series provides detailed information for 3 million to 4 million unique active vacancy ads. Data in HWOL are collected by WANTED Technologies Corporation from more than 16,000 online job websites, including corporate job boards and smaller job boards that serve niche markets. $\frac{23}{}$ The historical data begin in May 2005 and the Conference Board publishes annual revisions with the January data. HWOL data are the sum of postings from mid-month to mid-month and are aligned with the CPS unemployment job search time period for straightforward comparison. Data are released around the first of the month following the completed mid-month to mid-month period. For example, data published on December 1 contain job ads from October 15 to November 14. 
Vacancy counts are obtained through real-time database queries. Queries can be made at geographic, occupational, and industry levels (Figure 1 shows national aggregations). Although this section includes only what is most important for the indexes, more detailed information about the HWOL is included in Appendix B.

Unduplication. The HWOL attempts to reflect unduplicated ads. As the geographic level increases (e.g., from county to metropolitan area), an ad may appear more than once because neighboring counties may each have ads for the same job. Accordingly, a process is used for each query to eliminate duplicated ads across job sites using information such as a company's name, job title, and location. Approximately two-thirds of the ads are removed as duplicates.

Reliability. Because the HWOL is effectively a population count, $\underline{24}$ it is not subject to the standard sampling error and nonresponse errors embodied in the majority of statistical surveys. The HWOL data are subject to nonsampling error from (i) undercoverage resulting from missing a significant job board and smaller, local job boards and (ii) overcoverage resulting from the failure to eliminate all duplicate ads. Other errors could include ads incorrectly coded at the occupational, industrial, or geographic level. Approximately 40 percent of ads do not provide information about the employer. Accordingly, those ads do not have an industry recorded and thus could affect the reliability of calculations that use industry data.

\section{RESULTS}

In this section, we use the above-described data to compute six of the mismatch indexes described earlier: $I_{L i l i e n}, I_{J R 1}, I_{J R 2}, I_{J R 3}\left(I_{S S T V 1}\right), I_{J L S}$, and $I_{\text {Evans }}$. 25 We calculate the indexes between May 2005 and May 2012 for two types of mismatch-industrial and occupational-using two levels of disaggregation for each (Table 1). We first review the mismatch trends by index to understand how changes in the indexes compare with one another over the course of the sample. We then analyze the data for three separate periods to determine whether mismatch has changed during the Great Recession and, if so, its implication for labor markets. The periods for our study are as follows: pre-recession (May 2005-November 2007), Great Recession (December 2007June 2009), and post-recession (July 2009-May 2012). Lastly, we calculate the counterfactual unemployment rate described previously to infer the contribution of mismatch to the rise in the unemployment rate around the Great Recession. ${ }^{26}$ For greater tractability, we focus our analysis on the 19-industry and 22-occupation breakdowns.

We follow Şahin et al's (2012) approach and apply a Hodrick-Prescott filter to the computed indexes to remove high-frequency movements. $\frac{27}{}$ Furthermore, because approximately 40 percent of ads do not provide information on the employer (see the previous section), only around 45 percent of the unduplicated ads are assigned industry codes (see Figure 1). To address this issue, we assume that the proportion of ads that cannot be assigned a North American Industry Classification System (NAICS) code is homogeneous across all industry categories used in this article. While this assumption may not be very realistic, the results for our industry mismatch indexes show trends similar to the results of Şahin et al. (2012), who use Job Openings and Labor Turnover Survey (JOLTS) data (see Appendix B). Given this assumption, estimations of the $I_{J R 1}$, 


\section{Table 1}

Industrial and Occupational Mismatch at Two Levels of Disaggregation

\begin{tabular}{c} 
Industries (NAICS code) \\
\hline General level of disaggregation \\
12 Industries
\end{tabular}

Natural resources and mining $(11,21)$

Construction (23)

Manufacturing (31-33)

Wholesale and retail trade $(42,44-45)$

Transportation and utilities $(48-49,22)$

Information (51)

Financial activities $(52,53)$

Professional and business services $(54,55,56)$

Education and health services $(61,62)$

Leisure and hospitality $(71,72)$

Other services (81)

Public administration (92)

\section{Occupations (SOC code)}

\section{General level of disaggregation} 10 Occupations

Management, business, and financial $(11,13)$

Professional and related $(15, \ldots, 29)$

Service $(31, \ldots .39)$

Sales and related (41)

Office and administrative support (43)

Farming, fishing, and forestry (45)

Construction and extraction (47)

Installation, maintenance, and repair (49)

Production (51)

Transportation and material moving (53)

\section{Detailed level of disaggregation} 19 Industries

Agriculture, forestry, fishing and hunting (11)

Mining (21)

Utilities (22)

Construction (23)

Manufacturing (31-33)

Wholesale trade (42)

Retail trade (44-45)

Transportation and warehousing (48-49)

Information (51)

Finance and insurance (52)

Real estate and rental and leasing (53)

Professional, scientific, and technical services (54)

Business services $(55,56)$

Education services (61)

Health care and social assistance (61)

Arts, entertainment, and recreation (71)

Accommodation and food services (72)

Other services (81)

Public administration (92)

\section{Detailed level of disaggregation} 22 Occupations

Management (11)

Business and financial operations (13)

Computer and mathematical (12)

Architecture and engineering (17)

Life, physical, and social science (19)

Community and social services (21)

Legal (23)

Education, training, and library (25)

Arts, design, entertainment, sports, and media (27)

Health care practitioners and technical (29)

Health care support (31)

Protective service (33)

Food preparation and serving related (35)

Building and grounds cleaning and maintenance (37)

Personal care and service (39)

Sales and related (41)

Office and administrative support (43)

Farming, fishing, and forestry (45)

Construction and extraction (47)

Installation, maintenance, and repair (49)

Production (51)

Transportation and material moving (53) 
$I_{J R 2}, I_{E v a n s}$, and $I_{J R 3}\left(I_{S S T V 1}\right)$ indexes are not affected since sector $i$ 's share of total vacancies is unchanged from the missing ads.

\section{Mismatch Trends by Index}

Figure 2 plots each index's change in industrial mismatch (19 industries) over the entire sample relative to its value in May 2005. The behaviors of the six indexes vary considerably over the course of the 7-year sample. Among the 19-industry indexes, the $I_{J R 1}$ and $I_{J R 3}\left(I_{S S T V 1}\right)$ indexes share a similar pattern: Both increase over the course of the first two periods and then fall from their May 2005 values, yielding declines of approximately 27 percent and 35 percent, respectively. The $I_{J R 2}$ and $I_{\text {Evans }}$ indexes also share a similar long-term pattern: Although their paths generally differ in the pre-recession period, they increase through the recession and into the post-recession period, turning around in March 2010 and declining for the remainder of the sample; yet, at May 2012 their values are still considerably higher than their May 2005 values. The remaining indexes $-I_{L i l i e n}$ and $I_{J L S}-$ exhibit trends different from all the other indexes.

Figure 3, which plots occupational mismatch changes in the six indexes (22 occupations) over the sample, shows that most of the occupation mismatch indexes follow trends similar to those of their respective industry indexes. The main difference between the industry and occupation calculations in a given index is generally a function of scale: In the $I_{\text {Evans }}, I_{J L S}$, and $I_{\text {Lilien }}$ cases, the occupation indexes appear to be somewhat muted versions of the industry index trends; the reverse is true for the others.

Perhaps the most noticeable feature from Figures 2 and 3 is that the $I_{J R 2}$ and $I_{E v a n s}$ indexes exhibit changes of magnitude considerably greater than the other indexes. If we consider the long-term changes in the $I_{J R 2}$ index in context with data on unemployment and the labor force, the index would be expected to increase rapidly, while $I_{J R 1}$ and $I_{J R 3}\left(I_{S S T V 1}\right)$ would not. The reason for this difference rests in the underlying calculations of the Jackman and Roper (1987) indexes. Recall that $I_{J R 1}$ is derived by normalizing structural unemployment by the total stock of unem-

ployment, $\frac{\frac{1}{2} U \sum_{i}\left|\hat{u}_{i}-\hat{v}_{i}\right|}{U}$, whereas $I_{J R 2}$ is derived by normalizing structural unemployment by the labor force, $\frac{\frac{1}{2} U \sum_{i}\left|\hat{u}_{i}-\hat{v}_{i}\right|}{L}$. The second normalization results in $I_{J R 2}$ being equal to $I_{J R 1}$ scaled by $U / L$, the total stock of unemployed over the labor force. Therefore, the key to understanding the behavior of $I_{J R 2}$ is the $U / L$ ratio at each point of the long-term change calculation; in May 2005, $U / L=0.051$, with $U=7,651,000$ and $L=149,261,000$, compared with May 2012, when $U / L=0.082$, with $U=12,695,000$ and $L=154,998,000$. With these scalars in mind, the calculation for the percentage change over the sample (May 2005-May 2012) is altered from the basic $I_{J R 1}$ calculation, 


\section{Canon, Chen, Marifian}

Figure 2

Normalized 19-Industry Indexes: Changes Over Sample

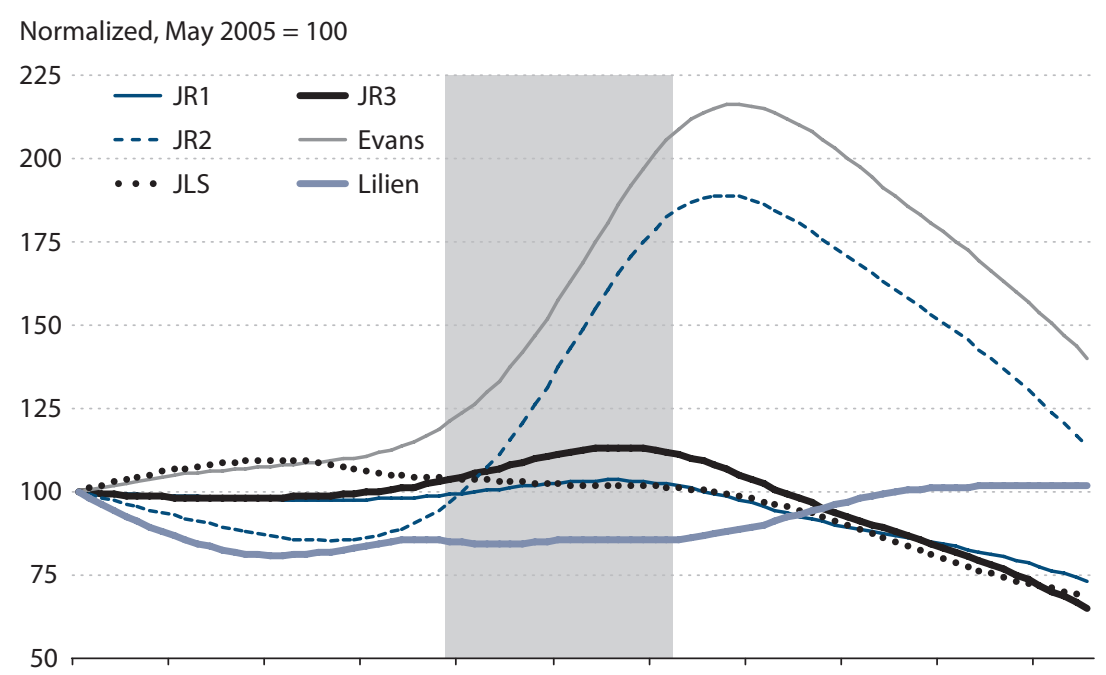

May-05 Jan-06 Sep-06 May-07 Jan-08 Sep-08 May-09 Jan-10 Sep-10 May-11 Jan-12

\section{Figure 3}

\section{Normalized 22-Industry Indexes: Changes Over Sample}

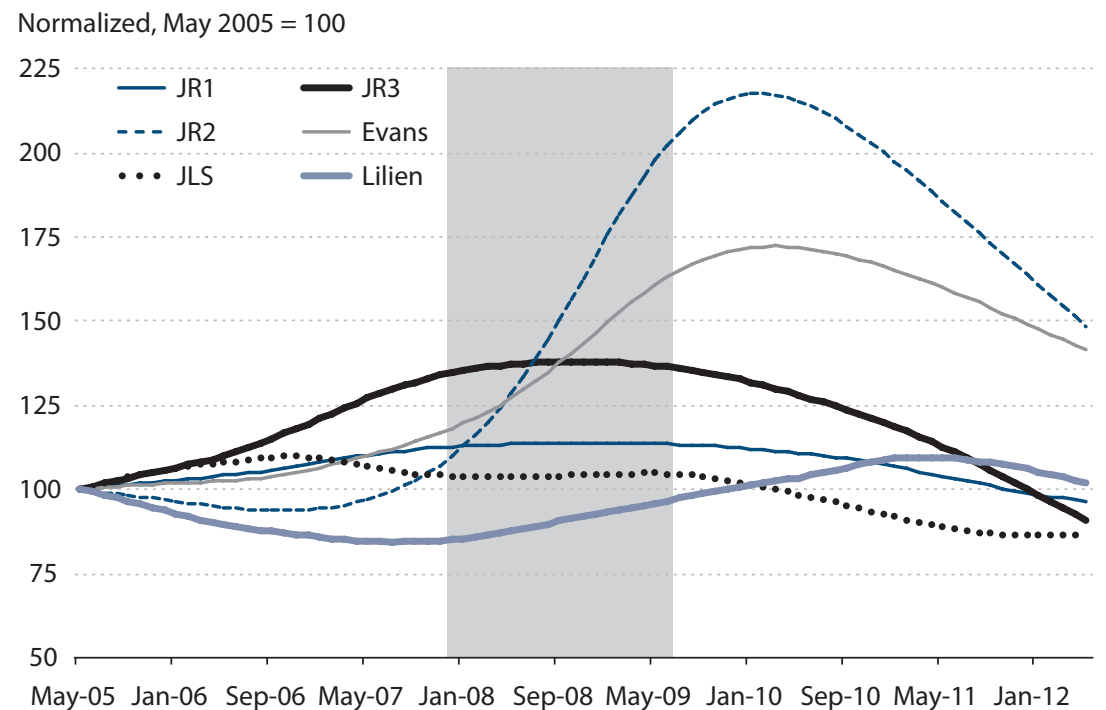




$$
\% \Delta I_{J R 1}=\frac{I_{I R 1}^{05-12}-I_{I R 1}^{05-05}}{I_{J R 1}^{05-05}},
$$

to

$$
\% \Delta I_{J R 2} \cong \frac{\left[\left(I_{I R 1}^{05-12 \star} 0.082\right)-\left(I_{J R 1}^{05-05} 0.051\right)\right]}{\left(I_{J R 1}^{05-05 \star 0.051)}\right.} .
$$

Adding in the scalars (what the $I_{J R 2}$ index adds to $I_{J R 1}$ ) adjusts the behavior of the $I_{J R 1}$ index such that the percentage change for $I_{J R 2}$ over the sample switches from negative to positive; the May 2012 index value is multiplied by 0.082 and the May 2005 index value is multiplied by 0.051 . This analysis explains why $I_{J R 2}$ differs from its related $I_{J R 1}$ and $I_{J R 3}\left(I_{S S T V 1}\right)$ indexes.

Comparing underlying formulas can also help shed light on why $I_{\text {Evans }}$ increases more than $I_{J R 1}$. The $I_{J R 1}$ index is calculated with just one deviation-namely, sectoral unemployment share deviations from sectoral vacancy shares. Alternatively, $I_{\text {Evans }}$ is calculated with two deviations: the deviation of sectoral differences from aggregate differences between the unemployment and vacancy rates. Therefore, $I_{\text {Evans }}$ adds an additional element of variation. If sectoral deviations are significantly different from the aggregate deviation, $I_{\text {Evans }}$ will capture additional volatility that $I_{J R 1}$ does not. In other words, the additional deviation can make $I_{\text {Evans }}$ more sensitive to unemployment or vacancy rate outliers, skewing the index relative to an index that is calculated with only one deviation, such as $I_{J R 1}$.

We now review the behaviors of each index over three periods-pre-recession, Great Recession, and post-recession - to understand each index's behavior in the context of its theoretical interpretation (i.e., its implication for labor markets).

\section{Pre-Recession Mismatch}

Over the pre-recession period (May 2005-November 2007), the behaviors of the indexes, both among the different indexes and within a particular index (industrial versus occupational mismatch), vary significantly. The most important point from the pre-recession period is that, despite the diverging trends, most of the industry and occupation indexes share a common element. Namely, regardless of the overall behavior over the period, most indexes began to increase in the months preceding the recession. This point is important to remember when considering increases in mismatch during the Great Recession. An increase in mismatch during the Great Recession with no preceding mismatch increase could suggest a cyclical component to the indexes. On the other hand, an increase in mismatch preceded by other such increases could be more indicative of other labor market shifts underway even before the Great Recession began.

The $I_{J R 1}$ and $I_{J R 3}\left(I_{S S T V 1}\right)$ industry mismatch indexes exhibit similar behaviors during the pre-recession period. Figure $\mathrm{C} 1 \stackrel{28}{2}$ shows that the $I_{J R 1}$ industry index, which is essentially flat in the 19-industry breakdown, declines until January 2007, when it turns around and increases for the remainder of the period. Over the entire pre-recession period, the index falls a slight 1.12 percent, from a May 2005 value of 0.418 to a November 2007 value of 0.413 . In other words, around 41 percent of the unemployed are in the wrong industry. 


\section{Canon, Chen, Marifian}

Alternatively, the $I_{J R 3} 19$-industry index, which measures the proportion of unemployment attributable to structural imbalance, offers perhaps a more intuitive mismatch index. The $I_{J R 3}\left(I_{S S T V 1}\right)$ (Figure $\mathrm{C} 2$ ) index declines very modestly in the first half of the period and then begins to increase in June 2006, eight months prior to $I_{J R 1}$. In contrast to the net decline in the $I_{J R 1}$ index, $I_{J R 3}\left(I_{S S T V 1}\right)$ increases 2.93 percent over the period. The 19 -industry values over the period for $I_{J R 3}$ imply that structural unemployment accounts for approximately 11 percent of the total unemployment.

The behaviors of the corresponding $I_{J R 1}$ and $I_{J R 3}\left(I_{S S T V 1}\right)$ occupation indexes (22 occupations) diverge from the marginally downward trend of the corresponding industry indexes. The $I_{J R 1}$ 22-occupation index exhibits an upward trend during the pre-recession period, with an overall period increase of 12.52 percent (Figure C3). The index values indicate that approximately 36 percent of the unemployed were in the wrong occupation in May 2005 (compared with approximately 42 percent in the wrong industry) and that percent increases to 40 in November 2007.

The pattern of the $I_{J R 3}\left(I_{S S T V 1}\right)$ 22-occupation index (Figure $C 4$ ) is a more pronounced version of the pattern seen in the $I_{J R 1}$ occupation index, with monthly percentage increases for $I_{J R 3}\left(I_{S S T V 1}\right)$ averaging 2.5 times those of $I_{J R 1}$. The $I_{J R 3}\left(I_{S S T V 1}\right)$ index begins the first half of the period with a steady incline, slightly picking up speed from June 2006 until January 2007, when it begins to decelerate. Over the entire period, the $I_{J R 3}\left(I_{S S T V 1}\right)$ 22-occupation index increases 33.87 percent, which is more than 2.5 times the increase seen in the $I_{J R 1}$ occupation index. The values of the $I_{J R 3}$ occupation index indicate that by December 2007 (the start of the Great Recession), approximately 15 percent of the unemployment across 22 occupation groups would be attributed to structural imbalance, up from 11 percent in May 2005. Clearly, both the $I_{J R 1}$ and $I_{J R 3}\left(I_{S S T V 1}\right)$ indexes indicate that occupational mismatch was on the rise even before the recession had begun. On the other hand, these indexes would suggest that industrial mismatch was little changed over the period leading up to the recession and began to increase slightly only in the six months preceding the recession.

We next consider the behavior of the $I_{J R 2}$ and $I_{\text {Evans }}$ indexes during the pre-recession period. $\underline{29}$ The net changes of the 19-industry indexes contrast with one another, while the occupation indexes both exhibit net increases over the period. The $I_{J R 2}$ industry index, which measures the share of the labor force in the wrong sector, demonstrates a slightly downward trend for the majority of the pre-recession period, falling 5.38 percent from May 2005 to November 2007 (Figure C5). This industry index reaches its minimum value of 1.652 in February 2007, after which it begins a period of acceleration that lasts for the remainder of the period. As described previously, the $I_{J R 2}$ index calculates imbalance as absolute deviations of sectoral unemployment shares from sectoral vacancy shares, weighted by one-half the aggregate unemployment-to-labor ratio. While $I_{\text {Evans }}$ is similar to $I_{J R 2}$ in that both indexes measure imbalance as a share of the labor force, $I_{\text {Evans }}$ calculates imbalance as one-half the deviation of the sectoral difference between unemployment rates and vacancy rates from the aggregate difference between the unemployment and vacancy rate, with each sector weighted by its labor force share (labor supply weights). The difference in calculations yields differing behaviors in the industry indexes, which do not share the same trends over the pre-recession period. In contrast to $I_{J R 2}$, which falls on net from 
May 2005 to November 2007, the $I_{\text {Evans }} 19$-industry index increases consistently over the period (Figure C6), rising 18.77 percent from a value of 0.798 in May 2005 to a November 2007 value of 0.948 .

For occupational mismatch, both the $I_{J R 2}$ and $I_{\text {Evans }}$ indexes increase on net over the period (7.19 percent and 16.81 percent, respectively), with paths different from each other but largely consistent with their corresponding industry indexes. The $I_{J R 2}$ occupation index (Figure C7) follows a softened version of the pattern for the industry index during the pre-recession period, declining slightly from its May 2005 value of 1.670 until it reaches its sample minimum of 1.564 in October 2006. Following this trough, the $I_{J R 2}$ occupation index begins to increase, with acceleration beginning around July 2007 and lasting through the recession period, mirroring the behavior of the corresponding industry index. Worth noting is that the $I_{J R 2}$ occupation index values are less than the industry values throughout the period. Among the six indexes, $I_{J R 1}$ and $I_{J R 2}$ are the only indexes for which the industry values are consistently greater than the occupation values; for both of these indexes, this trend reverses in the beginning of the post-recession period. Furthermore, the spread between the $I_{J R 2}$ industry and occupation indexes, which averages 0.13 percentage points over the period, narrows from a spread of 0.27 percentage points in May 2005 to a spread of 0.04 percentage points in November 2007 (see Figures C5 and C7).

As Figure C8 shows, the $I_{\text {Evans }}$ occupation index follows a trend similar to the $I_{\text {Evans }}$ industry index (see Figure C6). From May 2005 to November 2007, the index increases 16.81 percent (compared with the industry index's 18.77 percent increase), with an average monthly increase of less than 1 percent until August 2007. The $I_{\text {Evans }}$ occupation index values, which are 1.205 in May 2005 and 1.407 in November 2007, are greater than the values of the corresponding industry index over the period, with an average spread of 0.41 percentage points, but the trends of the two indexes are consistent.

The $I_{J L S}$ indexes, which are calculated as half the variance of the ratios of sectoral unemployment rates to the mean unemployment rate, provide an indication of the dispersion of unemployment rates across sectors. The industry and occupation indexes exhibit slight concavity over the period, increasing slightly from May 2005 until September 2006 (industry) and November 2006 (occupation) and subsequently falling for the remainder of the period (Figures C9 and $\mathrm{C} 10)$. Thus, the index indicates that in the first half of the pre-recession period, the dispersion of sectoral unemployment rates from the aggregate rate was slightly increasing, while over the second half it was decreasing to its original May 2005 level. On net, over the period the $I_{\text {ILS }}$ industry and occupation indexes increased only 4.12 and 4.14 percent, from May 2005 values of 0.100 and 0.134 , respectively, to values of 0.104 and 0.140 in November 2007 (see Figures C9 and $\mathrm{C} 10$ ).

Unlike the other indexes, which require unemployment and vacancy data to measure the degree of mismatch in the economy, $I_{\text {Lilien }}$ measures mismatch through calculations of employment dispersion across sectors. $\frac{30}{}$ Figure $\mathrm{C} 11$ plots the $I_{\text {Lilien }}$ 19-industry index, which experiences a sharp decrease in the first year of the pre-recession period, falling from a May 2005 value of 1.745 to a sample low of 1.410 in October 2006. Following this trough, the index recovers slightly to 1.489 by November 2007. This index's decline of 14.65 percent from May 2005 to November 
Table 2

Indexes that Increased During the Great Recession

\begin{tabular}{lccc} 
Index & $\begin{array}{c}\text { Type of } \\
\text { mismatch }\end{array}$ & $\begin{array}{c}\text { Increase (\%) preceding } \\
\text { Great Recession }\end{array}$ & $\begin{array}{c}\text { Increase (\%) over } \\
\text { Great Recession period }\end{array}$ \\
\hline$I_{J R 1}$ & Industrial & 1.13 & 3.49 \\
$I_{J R 3}\left(I_{S S T V 1}\right)$ & Industrial & 4.96 & 8.79 \\
$I_{J R 2}$ & Industrial & 10.93 & 92.83 \\
$I_{J R 2}$ & Occupational & 14.43 & 88.79 \\
$I_{E v a n s}$ & Industrial & 18.77 & 73.82 \\
$I_{E v a n s}$ & Occupational & 16.89 & 39.69 \\
$I_{J R 1}$ & Occupational & 12.52 & 0.80 \\
$I_{J R 3}\left(I_{S S T V 1}\right)$ & Occupational & 33.87 & 1.98
\end{tabular}

NOTE: All but two of the indexes increased during the Great Recession. For the $I_{J R 1}$ and $I_{J R 3}\left(I_{S S T V 1}\right)$ 22-occupation indexes, most increases were completed before the recession with only minimal increases during the Great Recession.

2007 is the largest of the 19-industry indexes over the pre-recession period. At the 22-occupation level, the $I_{\text {Lilien }}$ index also declines, falling 15.27 percent over the pre-recession period (Figure C12). Like its corresponding industry index, the $I_{\text {Lilien }}$ occupation index reaches its sample low during the pre-recession period, with a minimum value of 1.425 in July 2007, about 9 months after the industry index's minimum value.

\section{Great Recession Mismatch}

Similar to the pre-recession period, the behaviors of most indexes differ over the Great Recession period (December 2007-July 2009). Despite their different paths, four of the six 19industry indexes increase, and the remaining two indexes $\left(I_{J L S}\right.$ and $\left.I_{L i l i e n}\right)$ are approximately flat. The 22-occupation $I_{J R 2}, I_{\text {Evans }}$ and $I_{\text {Lilien }}$ indexes increase over the period, while $I_{J R 1}, I_{J R 3}\left(I_{S S T V 1}\right)$, and $I_{J L S}$ are essentially flat, exhibiting only minimal increases, if any. As during the pre-recession period, the $I_{J R 1}$ and $I_{J R 3}\left(I_{S S T V 1}\right)$ industry indexes follow a comparable trend, while the corresponding occupation indexes are flatter, with $I_{J R 3}\left(I_{S S T V 1}\right)$ exhibiting slightly more concavity. The $I_{J R 2}$ industry index behavior is similar to that of $I_{\text {Evans }}$ : Both increase significantly from values that are relatively low for the entire sample. The trends for the $I_{J R 2}$ and $I_{E v a n s}$ occupation indexes are also similar to each other and their corresponding industry indexes over the period.

It is important to note that while many of the indexes did increase over the Great Recession, most already had begun increasing before the recession began (the $I_{\text {Lilien }} 19$-industry index and the $I_{J L S}$ indexes are the exceptions) (see Figures 2 and 3). Table 2 shows that all but two of the indexes increased during the Great Recession; the percentage increase over the Great Recession is listed in the far-right column. The table also shows the percentage by which each index increased before December 2007, when the Great Recession began. $\underline{31}$

As is clear from Table 2, most indexes began to increase in the pre-recession period. Six of the eight indexes, including $I_{J R 1}$ and $I_{J R 3}\left(I_{S S T V 1}\right) 19$-industry and both types of the $I_{J R 2}$ and $I_{E v a n s}$ 
indexes, exhibited increases over the Great Recession of greater magnitude than the increases in the pre-recession period. For the other two indexes-namely, the $I_{J R 1}$ and $I_{J R 3}\left(I_{S S T V 1}\right)$ 22-occupation indexes-most of the increases were completed before the recession and increased only minimally during the Great Recession. Even though the Great Recession accelerated the degree of mismatch for six of the eight indexes, it was not the initial catalyst of the increases; positive increases preceded the increases during the Great Recession for all eight indexes listed in the table.

The 19-industry $I_{J R 1}$ index values, which began to increase at the end of the pre-recession period, continued to increase through the first half of the Great Recession period; the index takes on a concave shape throughout the majority of the period. The index reaches a sample maximum value of 0.432 in January 2009 (see Figure C1), but this value is only 3.52 percent greater than the index's initial value of 0.418 in May 2005. Following its maximum value, the index declines for the remainder of the period, yielding an overall increase of 3.49 percent from December 2007 to June 2009. The corresponding occupation index (see Figure C3) takes a different path during the Great Recession, increasing a mere 0.80 percent. Although this index also reaches its maximum value in January 2009, most of the movement responsible for the index's generally concave shape occurs during the pre- and post-recession periods. It is interesting to note that the $I_{J R 1}$ industry and occupation values, which appeared to be converging over the course of the pre-recession period, began to diverge, given that the industry index increases while the occupation index remains constant. Also worth noting is that this is one of two indexes for which the industry values are consistently greater than the occupation values during the Great Recession period.

The $I_{J R 3}\left(I_{S S T V 1}\right)$ industry index (see Figure C2) mirrors the $I_{J R 1}$ industry index, exhibiting a concave shape throughout the majority of the period. It increases to a sample maximum of 0.127 in February 2009 and declines for the remainder of the period. This industry index increased 10.14 percent from December 2007 to February 2009, compared with 13.36 percent from May 2005 to February 2009. Because of the declines during the second half of the recession, however, the index's overall increase from December 2007 to June 2009 was slightly less at 8.79 percent. As for occupational mismatch, Figure C4 shows that the $I_{J R 3}\left(I_{S S T V 1}\right)$ 22-occupation index is significantly greater than the 19-industry index, with occupation values ranging from 0.151 to 0.155 during the Great Recession, compared with the industry index's range of 0.116 to 0.127 . Although the $I_{J R 3}\left(I_{S S T V 1}\right)$ occupation index reaches a sample maximum of 0.155 in November 2008 , the increase from the value at the beginning of the recession to the maximum value is only a slight 3.15 percent. As with the $I_{J R 1}$ occupation index, most of the increase in the $I_{J R 3}\left(I_{S S T V 1}\right)$ index from May 2005 to the sample maximum occurs during the pre-recession period.

Figure C5 shows the $I_{J R 2}$ industry index during the Great Recession. Like most of the other industry indexes, the increase in this index begins a few months before the recession and continues to accelerate until August 2008, approximately the midpoint of the recession. After this inflection point, the index decelerates slightly for the remainder of the period, increasing to the period maximum of 3.535 by June 2009. The total increase over the period is a substantial 92.83 percent. It is important to note why $I_{J R 3}$ demonstrates this rapid incline while $I_{J R 1}$ and $I_{J R 3}\left(I_{S S T V 1}\right)$ do not. As stated previously, $I_{J R 2}$ is effectively the same as $I_{J R 1}$ scaled by $U / L$, the total stock of 


\section{Canon, Chen, Marifian}

unemployed over the labor force. Since the unemployment level increases rapidly (specifically, by 7,465,000) from December 2007 to June 2009 and the labor force increases considerably less $(875,000)$ over the same period, it is no surprise that the net effect is that $I_{J R 2}$ mirrors the unemployment level, while $I_{J R 1}$ and $I_{J R 3}\left(I_{S S T V 1}\right)$ increase only slightly over the period. As shown in Figure C7, the behavior of the $I_{J R 2} 22$-occupation index during the Great Recession is very similar to the corresponding industry index (see Figure C5). Like the industry index, it accelerates throughout the recession period, slowing in approximately November 2008. Over the period, the occupation index increases 88.79 percent.

In contrast to their differing trends during the pre-recession period, over the Great Recession period the $I_{\text {Evans }}$ indexes follow a pattern very similar to that of the $I_{J R 2}$ indexes. Figure C6 shows the 19-industry $I_{\text {Evans }}$ index, which increases 73.32 percent from the beginning of the recession to the end. Like the $I_{J R 2}$ industry index, the $I_{\text {Evans }}$ index reaches its peak in December 2009, after the Great Recession ends. The trend of the $I_{\text {Evans }}$ occupation index (see Figure C8) is somewhat similar to the corresponding industry index, although the period increase of 39.69 percent is considerably less than the 73.32 percent increase at the industry level. Nevertheless, the $I_{\text {Evans }}$ occupational mismatch (22 occupations) value is 47 percent higher than the $I_{\text {Evans }}$ industrial measure (19 industries) at the beginning of the recession, although it falls to 20 percent by the end of the recession.

The $I_{J L S}$ indexes, shown in Figures C9 and C10, exhibit little change over the period. The 19-industry index declines a modest 2.50 percent over the period, while the 22-occupation index changes even less, with an increase of 0.52 percent. As previously noted, both the $I_{\text {Lilien }}$ 19-industry and 22-occupation indexes declined over the pre-recession period. Yet over the Great Recession period, the behaviors of the $I_{\text {Lilien }}$ indexes diverge. For the last 9 months of the pre-recession period and the first 5 months of the Great Recession, the industry index values are greater than those of the occupation index. For the remainder of the Great Recession period, however, the opposite is true. The $I_{\text {Lilien }} 19$-industry index is essentially flat over the Great Recession period, increasing a minimal 0.44 percent from December 2007 to June 2009 (see Figure C11). Figure C12 shows that, in contrast, the $I_{\text {Lilien }}$ 22-occupation index grows steadily over the period, resulting in a 14.09 percent increase from December 2007 to June 2009.

\section{Post-Recession Mismatch}

The labor market dynamics after the recession (July 2009-May 2012) were such that a variety of measures would offer comparable trends in their behavior. Over the post-recession period, all 19-industry and 22-occupation mismatch indexes exhibit modest to significant declines, with the exception of the $I_{\text {Lilien }}$ indexes, which increase steadily over the period.

For the 19-industry mismatch calculations, the $I_{J R 1}, I_{J R 2}, I_{J R 3}\left(I_{S S T V 1}\right), I_{E v a n s}$ and $I_{J L S}$ indexes all decline during the post-recession period. While the $I_{J R 2}$ and $I_{\text {Evans }}$ indexes (see Figures C5 and C6) reach their peaks a few months after the recession ends, $I_{J R 1}$ and $I_{J R 3}\left(I_{S S T V 1}\right)$ (see Figures $\mathrm{C} 1$ and C2) had already reached their sample maximums a few months before the end of the recession. As shown in Figure C1, the $I_{J R 1}$ industry index declines 28.54 percent, while the $I_{J R 2}$ index declines 37.74 percent (see Figure C5). The $I_{J R 3}\left(I_{S S T V 1}\right)$ industry index declines the most over the 
period, at 41.95 percent (see Figure C2). Falling somewhere in the middle of the indexes, the $I_{\text {Evans }}$ industry index fell 31.87 percent (see Figure C6), while the $I_{J L S} 19$-industry index declined 32.24 percent (see Figure C9). The only index that diverged from the industry group was the $I_{\text {Lilien }}$ 19-industry index; Figure C11 shows that this index rose 18.7 percent over the period, an increase that began immediately following the recession. This index indicates that sectoral employment's dispersion from the aggregate was increasing throughout the post-recession period, which implies that a greater number of workers would need to change sectors to adjust to shifts in employment demand. Yet despite the index's significant increase over the entire period, it began to taper in October 2011, and for the subsequent 8-month period it remained at a constant 1.777, suggesting a possible stagnation and perhaps the beginning stages of a trend reversal.

Like their corresponding 19-industry indexes, the 22-occupation indexes fall during the post-recession period in differing magnitudes. The $I_{J R 1}, I_{J R 3}\left(I_{S S T V 1}\right), I_{J R 2}, I_{E v a n s}$ and $I_{J L S}$ indexes fall 15.22 percent, 33.47 percent, 26.51 percent, 13.39 percent, and 17.10 percent, respectively, from July 2009 to May 2012. The exception is the 22-occupation $I_{\text {Lilien }}$ index, which increases 5.36 percent over the period (see Figure C12).

Figure $\mathrm{C} 3$ shows that the $I_{J R 1}$ occupation index continues to exhibit slight concavity over the first half of the post-recession period, switching to a linear path in the second half of the period. This index's decline of 15.22 percent is over half the magnitude of the industry decline (see Figure $\mathrm{C} 1)$. The $I_{J R 3}\left(I_{S S T V 1}\right)$ occupation index maintains its concave shape, as well as the declines that begin halfway through the recession (see Figure C4).

Of all the indexes, the pattern of the $I_{J R 2}$ occupation index (see Figure C7) most resembles that of its corresponding industry index (see Figure C5). Like the industry index, in the beginning of the post-recession period the $I_{J R 2}$ occupation index increases at a decelerated rate before reaching its sample peak, although the occupation index peaks a few months later in February 2010, compared with November 2009 for the industry index. From the beginning to the end of the post-recession period, the $I_{J R 2} 22$-occupation index falls 26.51 percent. Of note, the convergence of the $I_{J R 2}$ index trends with other indexes such as $I_{J R 1}$ and $I_{J R 3}\left(I_{S S T V 1}\right)$ can be explained by the fact that $U / L$ falls between 0.081 and 0.100 over the entire post-recession period.

The $I_{\text {Evans }}$ occupation indexes in Figure C8 follow a trend similar to the $I_{\text {Evans }}$ industry indexes. Also like the $I_{J R 2}$ occupation index (see Figure C7), the $I_{\text {Evans }}$ 22-occupation index increases in the first few months of the period before hitting its sample maximum of 2.076 in March 2010. The $I_{\text {Evans }}$ occupation index (see Figure C8) is much flatter than its corresponding industry index, falling only 13.39 percent, compared with the industry index's decline of 31.87 percent (see Figure C6). The $I_{J L S}$ occupation index (see Figure C10) falls 17.10 percent over the period, less than the 32.24 percent decline in the corresponding industry index (see Figure C9). Part of this difference stems from the tapering off of the occupation index in the last four months of the sample, in contrast to the consistent declines seen in the industry index throughout the period.

The last occupation index, $I_{\text {Lilien }}$, takes on trends somewhat similar to those of its corresponding industry index. Figure $\mathrm{C} 12$ shows that the 22-occupation index continues its increases from the recession period, reaching a sample maximum of 1.854 in March 2011. It subsequently 


\section{Canon, Chen, Marifian}

declines for the remainder of the period, falling 7.16 percent from its maximum to its final value of 1.721 in May 2012, but still 5.36 percent higher than its value at the beginning of the period.

\section{Counterfactual Unemployment}

In addition to computing the indexes for industrial and occupational mismatch, we use $I_{S S T V 1}$ to compute the counterfactual unemployment rate (the unemployment rate that prevails when there is no mismatch) presented in the previous section. $\frac{32}{2}$ Following Şahin et al. (2012), we calculate the counterfactual unemployment rate, which, when subtracted from the actual unemployment rate, indicates how much of the recent rise in the unemployment rate can be attributed to mismatch.

Figures 4 and 5 show the actual unemployment rate plotted with our two calculations of the counterfactual unemployment rates, which use (i) industries disaggregated into 12 and 19 categories and (ii) occupations disaggregated into 10 and 22 categories. The spread between the actual and the counterfactual unemployment rates is always greater than zero, even when the unemployment rate is low, indicating that mismatch unemployment exists throughout the sample. The counterfactuals tend to follow the path of the actual unemployment rate, with fluctuations appearing to lag the actual rate slightly. Figure 4 shows that the lesser-disaggregated indexes appear superimposed throughout the majority of the sample; alternatively, with the greater level of disaggregation, the industrial counterfactual unemployment rate generally falls at higher values than those for the occupational rate (see Figure 5).

Again, we focus our description of the data on the greater disaggregations, 19 industries and 22 occupations (see Figure 5). At the beginning of the pre-recession period, both the industrial and occupational counterfactual unemployment rate calculations have the same value at 3.60 percent. Over the entire period, both rates exhibit convex behavior, declining to lows of 2.63 percent (19-industry) and 2.47 (22-occupation) percent in April 2007. From then until the beginning of the recession, the values increase by 11.08 percent and 9.40 percent, respectively, to 2.93 percent and 2.70 percent unemployment in the absence of mismatch.

The counterfactual unemployment rates begin their rapid growth during the Great Recession, following the trend of the actual unemployment rate. Over the entire recession period, the actual, industrial counterfactual, and occupational counterfactual unemployment rates increase 102.13 percent, 127.06 percent, and 133.07 percent, respectively, from their initial values in November 2007, which suggests that the counterfactual unemployment rates (the rates in the absence of mismatch) responded more sensitively during the recession than the actual values. Also worth comparing is the slope of the counterfactuals versus the slope of the actual unemployment rate, specifically over the six-month period when the paths appear linear. The actual unemployment rate exhibits a steep increase of 42.62 percent from its September 2008 value of 6.10 percent to its March 2009 value of 8.70 , yet this increase is considerably less than the 65.21 percent increase exhibited by the occupation counterfactual unemployment rate from the October 2008 value of 3.55 percent to the April 2009 value of 5.87 percent.

From the beginning of the Great Recession to the unemployment rate peak in October 2009, the mismatch unemployment rate increased 1.28 percentage points in the industrial type and 1.44 percentage points in the occupational type. This result implies that the rise in industrial 


\section{Figure 4}

\section{Comparison of Actual and Counterfactual Unemployment Rates (lesser disaggregation)}

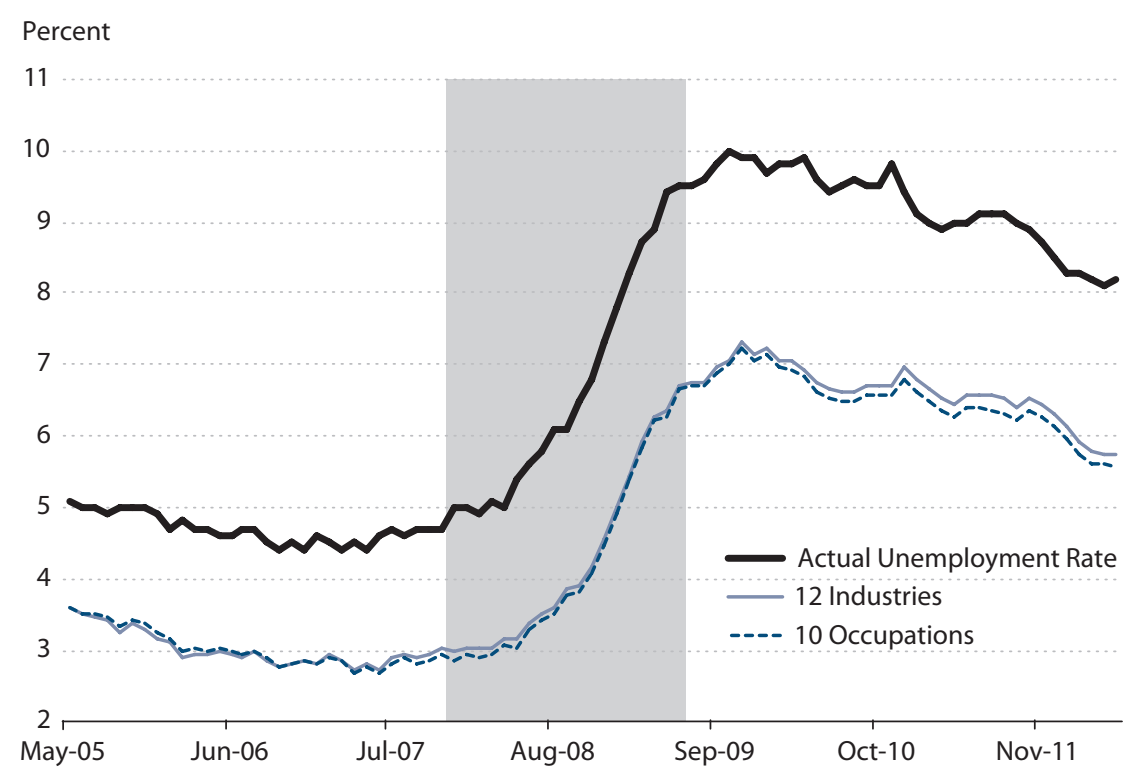

Figure 5

Comparison of Actual and Counterfactual Unemployment Rates (greater disaggregation)

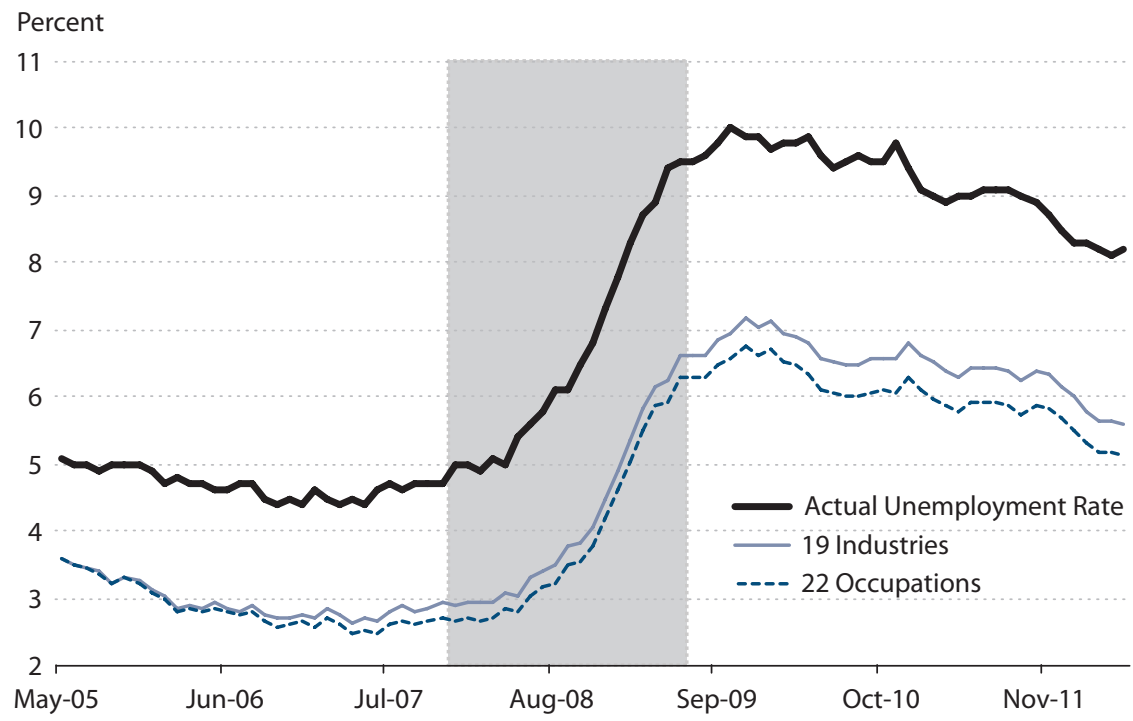




\section{Canon, Chen, Marifian}

and occupational mismatch, as measured by $I_{S S T V 1}$, can account for at most 2.72 percentage points of the 5.30-percentage-point increase in the unemployment rate from the start of the recession to the unemployment rate peak.

\section{CONCLUSION}

In this article, we provide an overview of five studies of labor market mismatch and use new U.S. vacancy data to calculate six of the corresponding indexes and a counterfactual unemployment rate. Similar to two decades ago, when the mismatch literature indicated that industrial and occupational mismatch played a nonnegligible role in the increase in European unemployment, we find notable increases in both industrial and occupational mismatch in the United States from May 2005 to November 2009. Our calculations of the counterfactual unemployment rates revealed that the total increase in industrial and occupational mismatch unemployment can account for at most 2.72 percentage points of the 5.30 -percentage-point increase in the unemployment rate from the beginning of the Great Recession to the unemployment rate peak in October 2009. Perhaps the most suitable indexes for describing mismatch in the United States are the $I_{J R 3}$ and $I_{S S T V 1}$ indexes, thanks to their intuitive interpretations and their ability to offer a measurement of the contribution of mismatch to unemployment. Alternatively, the $I_{J R 2}$ index perhaps is the least effective in providing an indication of mismatch. Because the $I_{J R 2}$ index is scaled by the unemployment and labor market level, it is susceptible to volatility in these statistics, which could overshadow important trends that can be gleaned from the dispersion of unemployment rates from vacancy rates. Furthermore, although computing the $I_{J L S}$ index is simple and requires only unemployment data, Padoa-Schioppa (2008b) concludes from Freeman (2008) and Bean and Pissarides (2008) that the assumption on wage functions is not realistic for countries such as the United Kingdom and United States, and thus its results should be approached with caution.

Some general limitations of mismatch indexes are noteworthy. First, they do not provide any information on the sources of mismatch. As a result, the indexes have limited relevance for the design of demand stimulation policies because the root of the problem is not identified. As Diamond (2011) affirms, "Insofar as direct measures of frictional or structural unemployment are dependent on the tightness of the labor market, they have limited relevance for the design of demand stimulation policies" (p. 1069). Another important drawback to existing mismatch indexes is that they do not capture any newly emerged labor sectors, which may bias the observed level of mismatch. Almost every theoretical framework of mismatch indexes assumes that the aggregate labor market is divided into a fixed number of sectors that differ significantly in terms of skills, locations, and so on. None of the indexes, however, accounts for potential changes in the number and the composition of sectors. As an example from recent history, the emergence of information technology over the past three decades may have created some new sectors while destroying some old ones. Empirically, it is currently difficult for mismatch indexes to capture this issue because of data limitations, but it is worthwhile to consider this issue in the theoretical framework for future research. 
We end by considering a recent alternative explanation of the forces that resulted in the jobless recovery in the United States. In their 2012 paper, Jaimovich and Siu argue that the jobless recovery is due to job polarization and that job polarization is a business cycle phenomenon. Job polarization describes the scenario in which employment grows at the tails of the skills distribution (high-skill and low-skill) but disappears for occupations in the middle of the skills distribution (middle-skill). Central to their analysis is the classification of occupations as either routine (middle-skill) or nonroutine (high-skill and low-skill). They believe that the jobless recovery is caused by the downturn-induced job losses in middle-skill occupations over the past 30 years that result from technological advances and labor offshoring.

If Jaimovich and Siu (2012) are correct, then our understanding of industrial mismatch would need to be altered: Industrial mismatch has little or nothing to do with vacancies existing in growing industries with unemployment in other, distressed industries. Instead, the industrial mismatch that exists would be characterized by a scenario in which the unemployed belong to a certain occupational type (routine jobs) and the job vacancies are for the opposite occupational type (nonroutine jobs), regardless of the industry. Assuming Jaimovich and Siu's (2012) conclusions are accurate, such analysis would capture most effectively the degree of mismatch in the economy, because it approaches the mismatch analysis with a framework based on the changing dynamics of developed labor markets. We believe such examination is a worthwhile avenue for future research in mismatch using unemployment and vacancy data. 


\section{APPENDIX A: INDEXES}

\section{The Lilien Index}

In "Sectoral Shifts and Cyclical Unemployment," Lilien (1982) responds to work by Lucas and Prescott (1974), pointing out that their derivation of the stationary equilibrium unemployment rate is dependent on the assumption that market-specific demands do not vary over different time periods. Lilien's analysis begins with the rejection of this assumption, which results in a time-variant equilibrium unemployment rate that moves with the quantity of labor reallocation (see p. 778).

To craft his dispersion index, Lilien (1982) first constructs hiring, separation, layoff, and accession functions that allow him to derive a model of the aggregate layoff rate. He assumes that the net hiring rate of a typical firm, $h_{t}$, can be expressed as the sum of the aggregate hiring rate $H_{t}$ and a random disturbance $\epsilon_{t}$. Specifically, the hiring function takes the form

$$
h_{t}=H_{t}+\epsilon_{t}
$$

where $\epsilon_{t}$ is assumed to be distributed with mean zero and variance $\sigma_{t}^{2}$ according to the density function $f\left(\epsilon_{t} \mid \sigma_{t}\right)$; $\sigma_{t}$ is the measure of sectoral dispersion of employment demand, whereby an increase in $\sigma_{t}$ occurs when a shock has a varying impact on firms.

Lilien (1982) proposes a proxy for $\sigma_{t}, \hat{\sigma}_{t}$, $\underline{33}$ which takes the following form:

$$
I_{\text {Lilien }}=\hat{\sigma}_{t}=\left[\sum_{i=1}^{n} \frac{x_{i t}}{X_{t}}\left(\Delta \log x_{i t}-\Delta \log X_{t}\right)^{2}\right]^{1 / 2},
$$

where $x_{i t}$ is the number of people employed in sector $i$ at time $t$ and $X_{t}$ is the total employment for all sectors. The index measures the dispersion of changes in sectoral employment from changes in aggregate employment. Lilien then uses the index to estimate the effect of dispersion on unemployment and aggregate layoffs. The unemployment equation is derived from a simple flow model, where the change of unemployment is equal to unemployment inflow $\underline{34}$ minus unemployment outflow.

\section{The Jackman and Roper Indexes}

Jackman and Roper's (1987) job hiring function takes the form

$$
H_{i}=V_{i} h\left(U_{i} / V_{i}\right) \quad\left(h^{\prime}>0, h^{\prime \prime}<0\right),
$$

where $U_{i}$ and $V_{i}$ are the number of unemployed and vacancies in sector $i$, respectively. They maximize the sum of $H_{i}$ across all sectors, subject to the constant $\sum_{i} U_{i}=U$ and the given $V_{i}$. When the first-order condition of the maximization problem is satisfied, the derivative of the hiring function is equal to a constant, indicating that the unemployment-to-vacancies ratio is identical across sectors, and they define this as a labor market at structural balance. From this maximization, a measure of structural unemployment directly follows, given by the number of 
unemployed workers needed to move from one sector to another to maximize aggregate hires. Specifically,

$$
S U=\frac{1}{2} \sum_{i}\left|U_{i}-(U / V) V_{i}\right|
$$

or, alternatively,

$$
S U=\frac{1}{2} U \sum_{i}\left|\hat{u}_{i}-\hat{v}_{i}\right|
$$

where $\hat{u}_{i}=\left(U_{i} / U\right)$ and $\hat{v}_{i}=\left(V_{i} / V\right)$ are sector $i$ 's shares of unemployed and vacancies, respectively.

\section{The Evans Index}

Evans's (1993) framework assumes short-run disequilibrium and looks at the "aggregate impact of sectoral imbalance on labour markets" (p. 440, footnote 1). Evans states that his theoretical orientation differs from that of other papers discussing labor market imbalance, such as those by Jackman, Layard, and Pissarides (1989) and Jackman, Layard, and Savouri (2008), who focus instead on equilibrium labor markets' frictional factors. Deviating from conventional macroeconomic models with aggregate supply and aggregate demand equations, $\frac{35}{2}$ Evans's framework assumes that wages are predetermined; as a result, labor market vacancies and unemployment enter the model. Under this framework, a partial equilibrium analysis of the aggregate supply side (see Hansen, 1970) shows that the degree of sectoral imbalance affects the position of the Beveridge curve (unemployment-vacancy [UV] curve). Accordingly, a neutral variation in aggregate demand results in movement along the UV curve, while a change in sectoral imbalance alters the position of the UV curve.

However, Evans notes that if (i) the demand for labor exhibits a nonneutral change and (ii) there is simultaneously a correlation across sectors between the elasticities of labor demand with respect to aggregate output and the net unemployment rates, then the index of sectoral imbalance can exhibit a cyclical pattern. Specifically, he notes that positive correlations would result in countercyclical behavior by the index, which could result in fluctuations in the unemployment rate being attributed to changes in sectoral imbalance when they are actually a function of demand changes. In such a case, Evans attempts to correct for the problem by first estimating the sectoral elasticities of labor demand with respect to aggregate output, and then using those estimates to remove the effects of variations in aggregate output on the index of sectoral imbalance. This method is at a disadvantage because the cyclical pattern is not corrected within the model itself.

\section{The Şahin et al. Indexes}

Şahin et al.'s (2012) benchmark economy $\underline{36}$ is composed of a large number of $i$ distinct labor markets/sectors. New production opportunities arise exogenously in each sector and correspond to job vacancies. Individuals in the economy are risk neutral and can either be employed in sector $i\left(e_{i}\right)$ or unemployed and searching for work in the same sector $\left(u_{i}\right)$. The authors do not 


\section{Canon, Chen, Marifian}

allow for on-the-job search. Labor market frictions exist, and the number of new hires $h_{i}$ in sector $i$ is given by the matching function $\Phi \cdot \phi_{i} \cdot m\left(u_{i}, v_{i}\right)$, which matches unemployed workers $u_{i}$ with vacancies $v_{i}$. The variable $\Phi$ represents the aggregate efficiency component, which is the same for all sectors, while the sector-varying matching efficiency is given by $\phi_{i}$; together, $\Phi$ and $\phi_{i}$ measure the matching efficiency in sector $i$. The component $m$ is assumed to be strictly concave, strictly increasing, and homogeneous of degree one. The authors also assume that (i) existing matches produce units of output $Z$ (homogeneous sectoral labor productivities) and (ii) the rates of match-destroying $\Delta$ are the same for all sectors (homogeneous sectoral job-destruction rates). Therefore, in the benchmark model, the only two sources of heterogeneity across sectors come from the number of vacancies $v_{i}$ and the matching efficiency $\phi_{i}$.

In this environment, the model operates as follows: $Z, \Delta$, and $\Phi$ are exogenous aggregate shocks, which are observed at the beginning of the period with aggregate vacancies $\mathbf{v}$ and matching efficiencies $\phi$. Also given at the beginning of the period is the distribution of active matches across labor markets, $\mathbf{e}=\left\{e_{1}, \ldots, e_{I}\right\}$, and the total number of unemployed workers $u$. Unemployed workers freely choose a labor market, and then the matching process takes place according to the matching function, yielding $h_{i}$ in each market. Production occurs with existing matches $e_{i}$ and the new matches $h_{i}$; a share $\Delta$ of the matches are destroyed in each market $i$. Thus, at the end of the period, the employment distribution and the number of unemployed workers are determined for the next period.

Following Jackman and Roper (1987), Şahin et al. (2012) assume that the individual-market matching function $m\left(u_{i t}, v_{i t}\right)$ is Cobb-Douglas, taking the form

$$
h_{i t}=\Phi_{t} \phi_{i t} v_{i t}^{\alpha} u_{i t}^{1-\alpha}
$$

where $h_{i t}$ are hires in sector $i$ at date $t$ and $\alpha \in(0,1)$ is the vacancy share for all sectors. Then, the first index (for the benchmark environment) is

$$
I_{S S T V 1 \phi}=M_{\phi t}=1-\frac{h_{t}}{h_{t}^{*}}=1-\sum_{i=1}^{I}\left(\frac{\phi_{i t}}{\bar{\phi}_{t}}\right)\left(\frac{v_{i t}}{v_{t}}\right)^{\alpha}\left(\frac{u_{i t}}{u_{t}}\right)^{1-\alpha},
$$

where $h_{t}^{*}$ is the planner's hires and $h_{t}$ is the observed level of aggregate hires.

\section{APPENDIX B: DATA}

\section{HWOL Vacancy Data}

General. Ad-scraping is very common and the HWOL program identifies and eliminates from collection any job boards that are simply aggregators of ads from other job boards (and therefore do not offer any new or unique ads). Each year the job board sources change to (i) stay up-to-date with new sources and (ii) drop existing sources that primarily maintain postings from other job boards. New job boards are identified based on independent research and recommendations from industry sources. 
Geographic, Occupational, and Industry Levels. Geographic levels available for the job posts include metropolitan area, state, regional, and national levels. Geographic identities are recorded using Federal Information Processing Standards (FIPS) codes for ads at the county level, and metropolitan levels use the 2005 Office of Management and Budget (OMB) countybased definitions for metropolitan statistical areas (MSAs); regional levels use U.S. Census Bureau region definitions. Counts by Census regions are the direct sum of the respective state counts (including the District of Columbia). The national count is a direct sum of the state counts, plus ads designated as nationwide for their location requirement. A job post's area code is assigned based on the location cited in the text of the ad itself. Approximately 93 percent of the ads are coded to a county or city level, 5 percent are coded as statewide ads, and 2 percent are coded as nationwide.

The job posts are also classified by occupation and industry. Occupation codes use the 2000 OMB Standard Occupational Classification (SOC) system. The codes are assigned to the ads by an autocoder 37 at the six-digit and the eight-digit $\mathrm{O}^{\star} \mathrm{Net}$ level based on the job titles and job descriptions. The Conference Board periodically updates the $\mathrm{O}^{\star} \mathrm{Net}$ classification of HWOL data and reclassifies the entire HWOL database with new federal government revisions to the SOC manual. Industry codes are determined using the advertiser's name listed on the ads. The advertiser's name is then searched in the Dun \& Bradstreet database of companies, and six-digit North American Industry Classification System (NAICS) codes are taken from there. Because approximately 40 percent of ads do not provide information about the employer, it is difficult to identify the industry for these ads. For employers that can be identified, industry code assignments are very accurate.

Unduplication. Ads are first unduplicated at the Census Bureau's place code level (the lowest level of geographic coding). Additional unduplication is performed as geographic scope increases. If the identical ad appears in two different counties in the same MSA, it would be counted separately in each of the counties but would be counted only once at the MSA level (i.e., one of the ads would be treated as a duplicate in the MSA total). The same procedure applies to counting ads at the state level. Accordingly, there is no direct additivity from the county level to the MSA, state, or national level because summing the lower levels of geography (i.e., counties) produces a larger number of vacancies than will be retrieved by a query at higher geographic (i.e., MSA or state) levels.

In a limited number of instances, duplication can also occur from inaccurate coding of occupations. According to the Conference Board, the autocoder is able to assign occupation codes to 96 percent to 99 percent of all unduplicated ads. If two ads that are unduplicated in the U.S. total query are assigned different six-digit SOC codes, then they would both appear in their independent SOC code tabulations and thus would fail to be identified as duplicates in the occupation code query. $\frac{38}{}$ As such, the number of ads aggregated by adding all occupations is slightly larger (on average 1 percent) than the number obtained in the U.S. total query, even though not all ads are assigned an occupation code (see Figure 1). This problem is unlikely to have a significant effect on computation of mismatch indexes.

Other Data Series Relating to Vacancies. HWOL's national ads count trend is very similar to that indicated by another vacancy dataset, the Bureau of Labor Statistics' (BLS) Job Openings 
Figure B1

HWOL Data Compared with JOLTS Data (U.S. Totals, May 2005-May 2012)

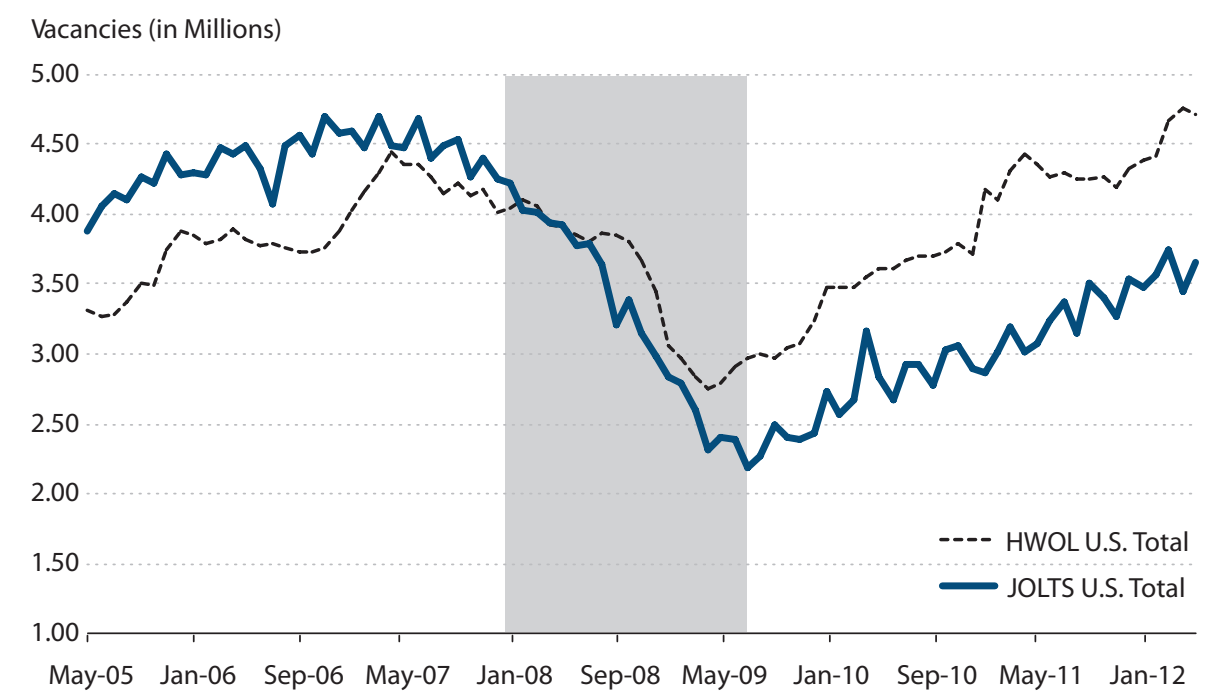

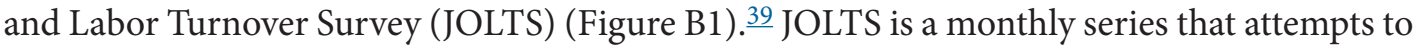
provide a broad national picture of U.S. hiring activity. JOLTS collects monthly data of job openings, separations, and hires from a sampling of 16,000 of 7 million nonfarm business establishments. JOLTS data are released roughly a month after their reference period and are available for December 2000 onward. $\underline{40}$ The definition of a job opening in JOLTS also allows it to provide an accurate estimate for national job vacancies. .11 The JOLTS definition of hires includes rehires and hires of people who were previously not in the labor force. A disadvantage of JOLTS data is that they can be broken down into only 4 Census regions and 18 broad industries at the national level. In contrast, HWOL's geographic completeness and occupational detail enable the computation of regional and occupational mismatch; HWOL also provides sufficient vacancy information for computing mismatch at more-disaggregated levels.

An additional alternative source of vacancy data is the Conference Board's Help Wanted Index (HWI), which offers an index for the number of ads in 51 leading newspapers from their respective cities. $\underline{42}$ It is the only known source that provides estimates for national job vacancies before 2000. The HWI has data from 1951 to the second quarter of 2010, when it was discontinued. The series does not provide actual counts of newspaper ads and it does not offer any industrial or occupational information. 


\section{APPENDIX C: INDUSTRY AND OCCUPATION INDEXES}

\section{Figure C1}

\section{$I_{J R 1}$ Industry Indexes}

Share of Unemployment in the Wrong Sector

0.45

0.40

0.35

0.30

0.25

0.20

0.15

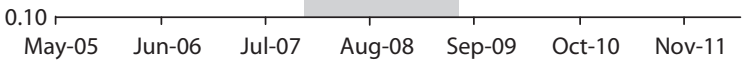

\section{Figure C3}

\section{$I_{J 1}$ Occupation Indexes}

Share of Unemployment in the Wrong Sector

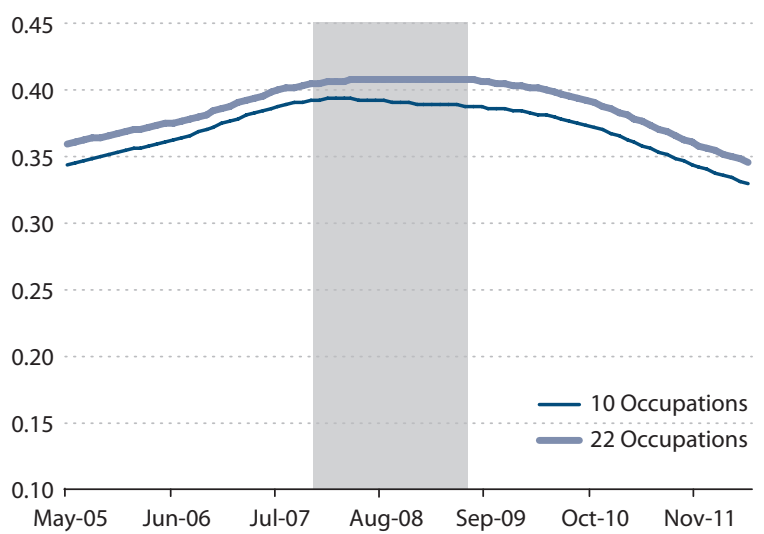

Figure $\mathrm{C} 2$

\section{$I_{J R 3}\left(I_{S S T V 1}\right)$ Industry Indexes}

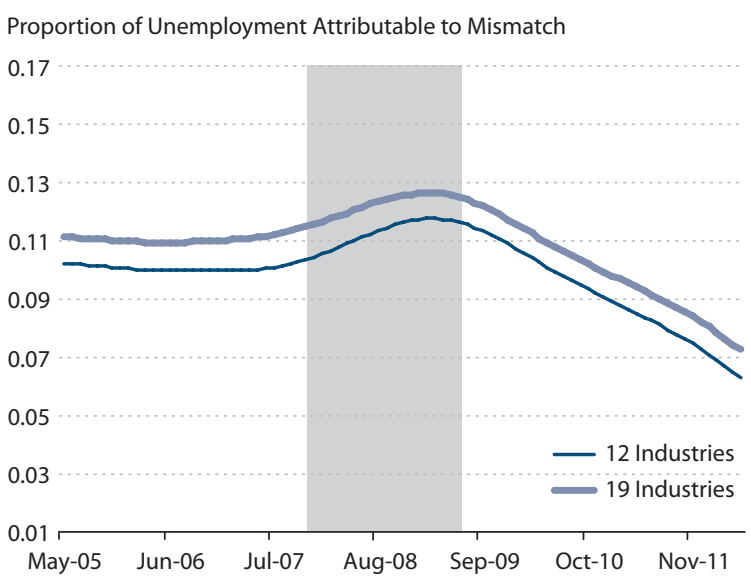

\section{Figure C4}

\section{$I_{J R 3}\left(I_{S S T V 1}\right)$ Occupation Indexes}

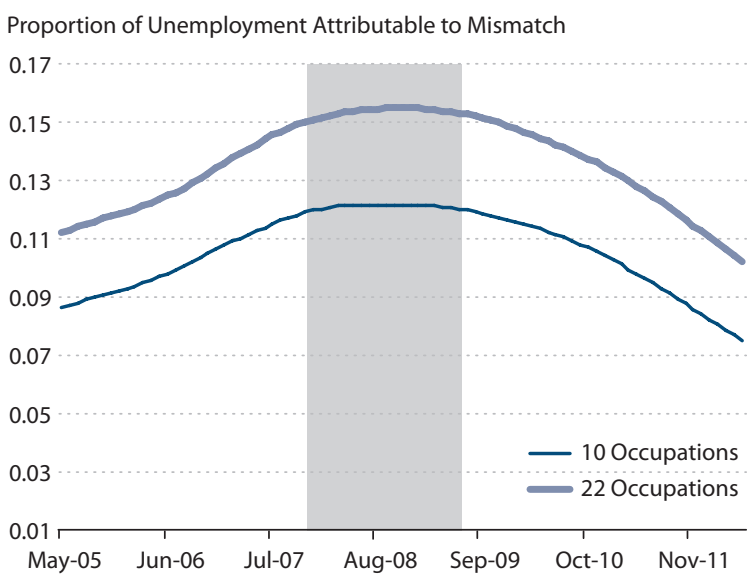




\section{Figure C5}

\section{$I_{J R 2}$ Industry Indexes}

Percent of Labor Force in the Wrong Sector

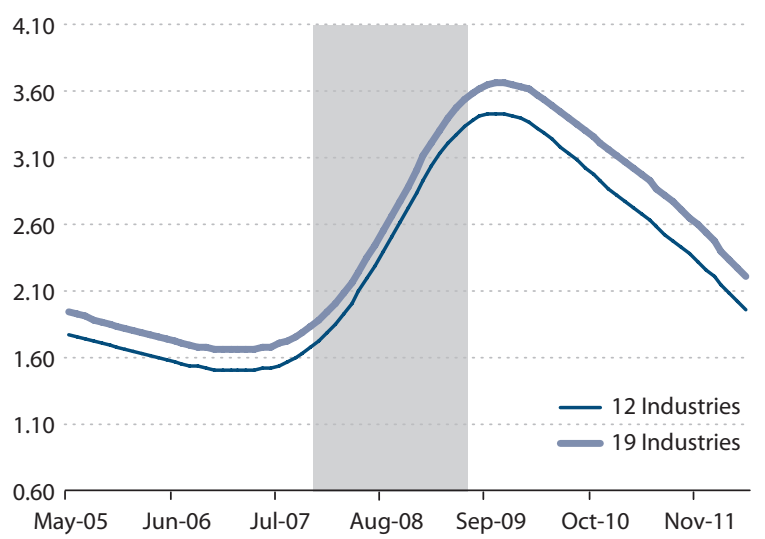

\section{Figure C7}

\section{$I_{J R 2}$ Occupation Indexes}

Percent of Labor Force in the Wrong Sector

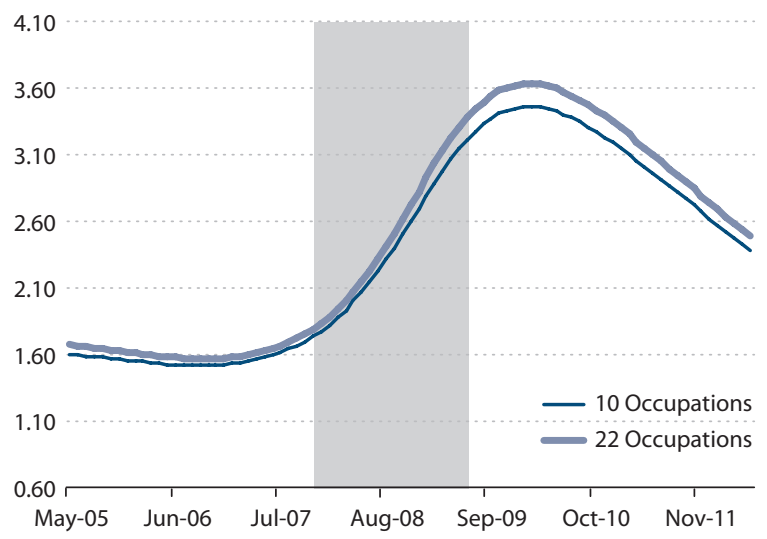

\section{Figure C6}

\section{$I_{\text {Evans }}$ Industry Indexes}

Average Deviation of the Percentage Difference Between Labor Supply and Demand Across Sectors

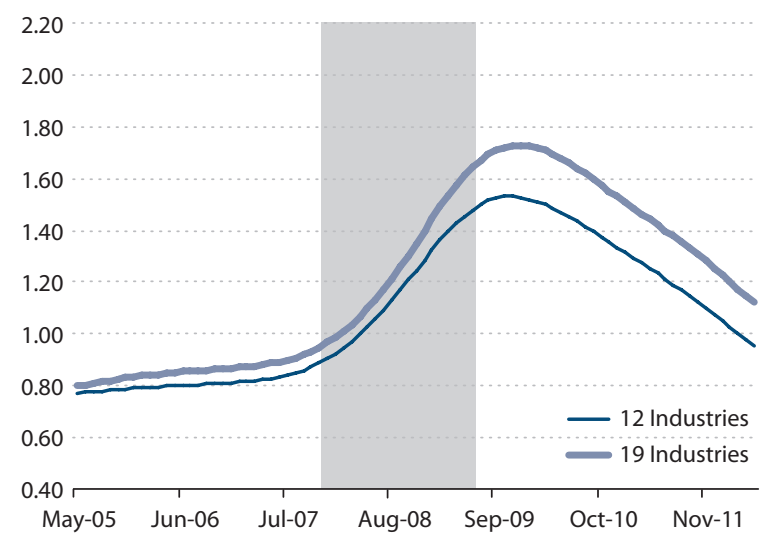

\section{Figure C8}

\section{$I_{\text {Evans }}$ Occupation Indexes}

Average Deviation of the Percentage Difference Between Labor Supply and Demand Across Sectors

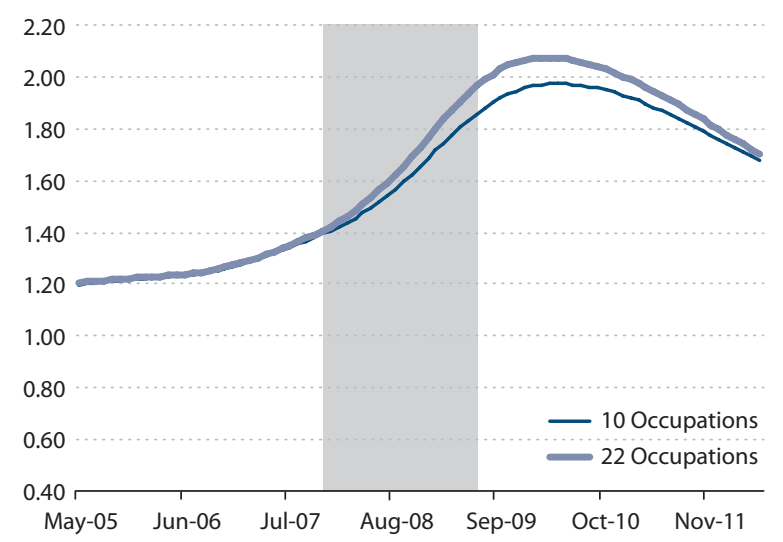




\section{Figure C9}

\section{$I_{J L S}$ Industry Indexes}

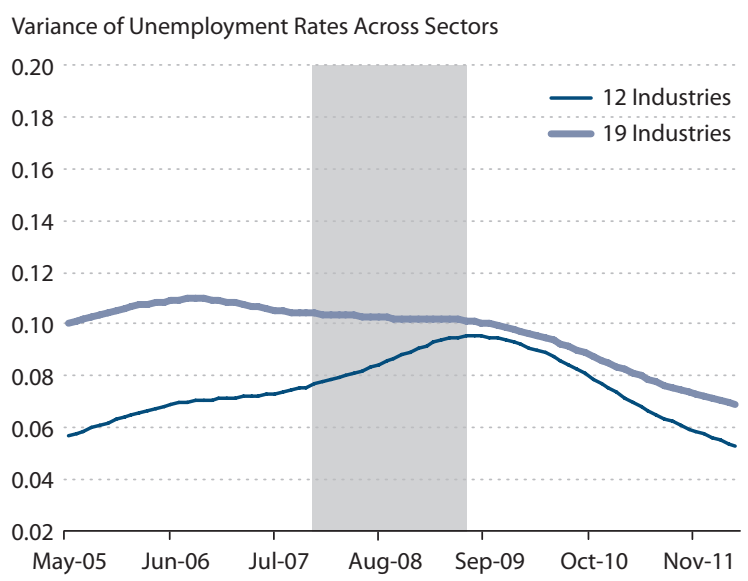

\section{Figure C11}

\section{$I_{\text {Lilien }}$ Industry Indexes}

Percent Log Deviations of Sectoral Employment from Total Employment (Scaled by 100)

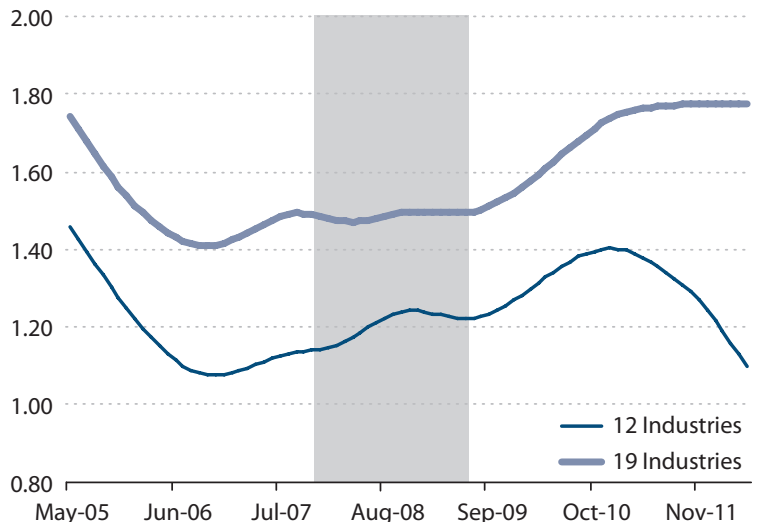

\section{Figure $\mathrm{C} 10$}

\section{$I_{J L S}$ Occupation Indexes}

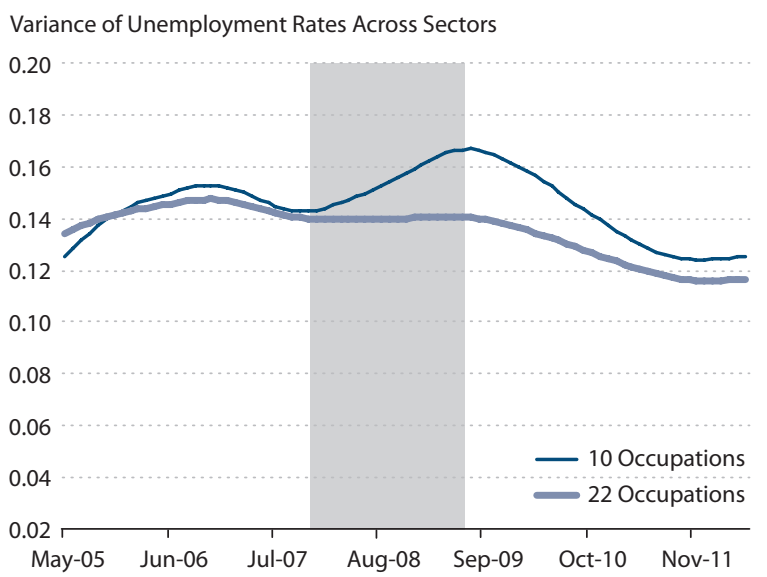

\section{Figure C12}

\section{$I_{\text {Lilien }}$ Occupation Indexes}

Percent Log Deviations of Sectoral Employment from Total Employment (Scaled by 100)

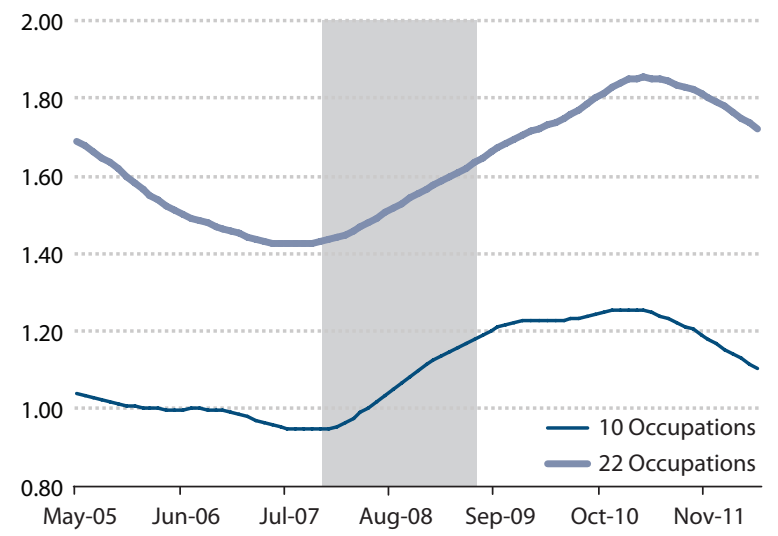




\section{Canon, Chen, Marifian}

\section{NOTES}

1 See the Conference Board Help Wanted OnLine (HWOL) job advertisements data series shown in Figure 1 (see http://www.conference-board.org/data/helpwantedonline.cfm).

2 Among economists and policymakers, some frequently discussed reasons for this jobless recovery include labor mismatch, extended unemployment insurance benefits, and low aggregate labor demand. For examples, see Şahin et al. (2012), Farber and Valletta (2011), and Elsby et al. (2011).

$\underline{3}$ They conclude that negative equity significantly reduced the mobility of homeowners.

4 The Beveridge curve is the empirical and negative relationship between the unemployment rate (typically plotted on the $x$-axis) and job vacancy rate ( $y$-axis). If the Beveridge curve moves outward (inward), then a given vacancy rate is associated with a higher (lower) unemployment rate.

5 See Padoa-Schioppa (2008a) for a collection of papers on this issue.

$\underline{6}$ Lilien sees this point-combined with the fact that service industry employment increased in all three downturns (1970-71, 1975, 1980)—as evidence that sectoral shifts contributed to the economic downturns, as opposed to the downturns causing temporary shifts in employment (see p. 779).

$\underline{7}$ From Lilien's point of view, at that time in the literature's development, the importance of hiring condition dispersion in determining the aggregate layoff rate was not well understood. However, he simultaneously noted that it was widely observed that some firms issue layoffs when others are hiring new workers. To emphasize the importance of capturing this variance in hiring in the layoff function (and, ultimately, in his unemployment model), he uses the following example: Suppose that in one economy, all the firms are growing at 2 percent, while in another economy, half of the firms are growing at 8 percent and half are shrinking by 4 percent. Even though these two economies have identical aggregate employment growth rates, the first economy would have many fewer layoffs than the second.

8 Whereas Jackman and Roper define labor market frictions as being characterized by the "coexistence of unemployment and unfilled vacancies within a sector," they believe that structural imbalance is characterized by unemployment in some sectors (beyond any frictional unemployment) coexisting with vacancies in other sectors (beyond any frictional vacancies).

9 They assume that the labor market is divided into a number of sectors, viewing job characteristics as homogeneous within each sector but significantly different across sectors. Their theoretical basis stems from a job hiring function, which is assumed to be convex, linear homogeneous, and the same in all sectors.

10 They note that "wrong" is only in relation to the definition of structural balance (see p. 12).

11 Petrongolo and Pissarides (2001) conclude from studies of matching functions that the Cobb-Douglas form is a good approximation.

12 Aggregate hires is assumed to equal separations at all times (i.e., aggregate employment is unchanged).

$\underline{13}$ See Appendix A for Evans's commentary of the effect of nonneutral changes.

14 They are referencing Evans (1985b).

15 Because the authors assume there are no frictions between sectors, unemployment at the optimal allocation is caused purely by the frictions within sectors. The matching function governs this relationship between unemployed workers and vacancies within a given market $i$.

16 Computation of $I_{S S T V 1 \phi}$ requires hiring data by sector to estimate the sector-specific matching efficiencies $\phi$. We choose instead to compute $I_{S S T V 1}$, which is described below.

$17 \phi_{i} m_{U}\left(\frac{v_{i}}{u_{i}^{*}}\right)$ gives the matching efficiency-weighted vacancy-to-unemployment ratio in sector $i$, where $u_{i}^{*}$ is the optimal allocation of unemployment in sector $i$ implied by the first-order condition and $m_{U}$ is the partial derivative of $m$ with respect to $u_{i}$.

18 Data on matching efficiency, labor productivity, and job destruction rates by sector are needed to compute $I_{\text {SSTV2 }}$.

19 According to the BLS, the lowest geographic levels of reliable estimates provided by the CPS are the state and 12 of the largest metropolitan statistical areas (MSAs). The Local Area Unemployment Statistics program provides monthly 
data for employment and unemployment at geographic areas smaller than states (U.S. Department of Labor, Bureau of Labor Statistics, 2009).

20 We seasonally adjust all series because some indexes, such as $I_{J L S}$ and $I_{\text {Lilien, }}$ use only unemployment and employment data, respectively. Therefore, these indexes could exhibit seasonal patterns that might not allow for comparison.

21 New ads are defined as unduplicated ads that did not appear in the previous reference period. Total ads are defined as unduplicated ads that appear in the reference period. Total ads include both new ads and ads from the previous month that have been reposted.

$\underline{22}$ Data sources for this section are the Conference Board Help Wanted OnLine ${ }^{\circledast}$ Data Series Technical Notes (August 2012; http://www.conference-board.org/pdf free/press/TechnicalPDF 4560 1343756152.pdf) and personal email communications with Jeanne Shu (May 2011, June 2011, July 2011, April 2012, and May 2012).

$\underline{23}$ However, the Conference Board states that it may not target smaller local Internet job boards in an area with a limited number of ads.

24 The number of online ads from HWOL provides an estimate of the actual count of job openings. When an ad is posted for a position that has multiple openings, it is counted as only one ad in HWOL.

$\underline{25}$ As mentioned previously, $I_{J R 3}$ is mathematically equivalent to $I_{S S T V 1}$ because of the assumption that vacancies are the only source of heterogeneity across sectors.

$\underline{26}$ Unlike Şahin et al. (2012), who use $I_{\text {SSTV2 }}$ to calculate the counterfactual unemployment rate, we use $I_{S S T V 1}$.

${ }_{27}$ As an alternative to the Hodrick-Prescott filter, we also calculated a 3-month moving average for each of the indexes and the trends are consistent. We chose to use the Hodrick-Prescott filter because the trends are smoother.

$\underline{28}$ Figure numbers that begin with " $\mathrm{C}$ " can be found in Appendix $C$, which provides a figure containing each index's 12and 19-industry breakdowns, as well as a figure containing each index's 10- and 22-occupation breakdowns.

$\underline{29}$ We multiply the $I_{J R 2}$ values by 100 .

30 We multiply the $I_{\text {Lilien }}$ values by 100 .

31 The starting point for this calculation is the pre-recession month when the index began an increase that lasted for the remainder of the period. The endpoint is November 2007. For example, the increase preceding the Great Recession for the $I_{J R 1}$ 19-industry index is measured as the percentage change over the period May 2006-November 2007, because in May 2006 the index began to increase and continued this increase for the remainder of the prerecession period (see Figure $\mathrm{C} 1$ ).

$\underline{32}$ In their paper, Şahin et al. use $I_{S S T V 2}$ to calculate the counterfactual unemployment rate. Since we do not compute $I_{S S T V 2}$, we use $I_{S S T V 1}$ instead.

33 Padoa-Schioppa (2008b) refers to $\hat{\sigma}_{t}$ as the "turbulence index" (see p. 2).

$\underline{34}$ The term $\sigma_{t}$ (dispersion) enters Lilien's equation of unemployment inflow through the layoff function. Layoffs, quits (including those who did not find employment before leaving their most recent job), and labor force entrants complete the flow into unemployment.

35 Evans explains that in traditional macroeconomic models (with aggregate supply and aggregate demand equations), sectoral imbalance functions through the aggregate supply side. Referencing Evans (1985a) and Evans (1989), he writes:

For example, in a stochastic disaggregated model with temporary sectoral wage floors and a gradual movement of labor between sectors...the position of the aggregate supply curve, in both the short-run and the long-run, depends upon the extent of imbalance between sectors. The degree of imbalance, which is increased from random sectoral shocks and diminished by equilibrating changes in sectoral wages and labour supplies, is appropriately measured, in the stochastic steady state, by the standard deviation of sectoral excess demands for labor, computed at the (temporary) nominal wage floors.

[A]n increase in aggregate demand leads, in the short run, to a decrease in unemployment in excess supply sectors and an increase in wages and prices in excess demand sectors. There is no role for vacancies because of the assumed upward flexibility of wages (pp. 440-41). 


\section{Canon, Chen, Marifian}

$\underline{36}$ Shimer (2007) develops an alternative theoretical framework for mismatch.

37 The Conference Board states that the autocoder software is selected for its accuracy. The HWOL time series will be converted to the 2010 SOC standard with the release of the 2013 annual revision.

$\underline{38}$ This issue will be corrected with the release of the 2013 annual revision, which implements a methodology change where all HWOL counts will now be created by directly summing unduplicated city-level counts.

39 The trend of ad counts by broad industry categories in HWOL is also very similar to what is shown by JOLTS, although the levels are quite different because of the missing industry information for online ads.

40 Job openings for a certain month are defined as the number of openings on the last day of the reference month.

41 See Shimer (2005) for a discussion.

$\underline{42}$ See Abraham (1987) for a detailed description of these data.

\section{REFERENCES}

Abraham, Katharine G. “Help-Wanted Advertising, Job Vacancies, and Unemployment." Brookings Papers on Economic Activity, 1987, 18(1), pp. 207-48.

Abraham, Katharine G. and Katz, Lawrence F. "Cyclical, Unemployment: Sectoral Shifts or Aggregate Disturbances?" Journal of Political Economy, June 1986, 94(3 Part 1), pp. 507-22.

Bean, Charles R. and Pissarides, Christopher A. "Skill Shortages and Structural Unemployment in Britain: A (Mis)matching Approach," in Fiorella Padoa-Schioppa, ed., Mismatch and Labour Mobility. Cambridge, UK: Cambridge University Press, 2008, pp. 325-53.

Blanchard, Olivier J. and Diamond, Peter A. "The Beveridge Curve." Brookings Papers on Economic Activity, 1989, 20(1), pp. 1-76.

Diamond, Peter. “Unemployment, Vacancies, Wages." American Economic Review, June 2011, 101(4), pp. 1045-72.

Elsby, Michael W.; Hobijn, Bart; Şahin, Ayşegül and Valletta, Robert G. “The Labor Market in the Great Recession-An Update to September 2011." Brookings Papers on Economic Activity, Fall 2011, pp. 353-84.

Evans, George W. "Bottlenecks and the Phillips Curve: A Disaggregated Keynesian Model of Inflation, Output and Unemployment." Economic Journal, June 1985a, 95, pp. 345-57.

Evans, George W. "A Cyclically Adjusted Index of Structural Imbalances," Unpublished manuscript, London School of Economics, 1985b.

Evans, George W. "The Conduct of Monetary Policy and the Natural Rate of Unemployment." Journal of Money, Credit, and Banking, November 1989, 21(4), 498-507.

Evans, George W. "Sectoral Imbalance and Unemployment in the United Kingdom: 1963-84." Oxford Economic Papers, July 1993, 45(3), pp. 440-56.

Farber, Henry S. and Valletta, Robert. “Do Extended Unemployment Benefits Lengthen Unemployment Spells? Evidence from Recent Cycles in the U.S. Labor Market." NBER Working Paper No. 19048, National Bureau of Economic Research, May 2013; http://www.nber.org/papers/w19048.pdf?new window=1.

Ferreira, Fernando; Gyourko, Joseph and Joseph, Tracy. "Housing Busts and Household Mobility." Journal of Urban Economics, July 2010, 68(1), pp. 34-45.

Freeman, Richard B. "Labour Market Tightness and the Mismatch between Demand and Supply of Less-Educated Young Men in the United States in the 1980s," in Fiorella Padoa-Schioppa, ed., Mismatch and Labour Mobility. Cambridge, UK: Cambridge University Press, 2008, pp. 360-81.

Hansen, Bent. "Excess Demand, Unemployment, Vacancies, and Wages." Quarterly Journal of Economics, February 1970, 84(1), pp. 1-23.

Hobijn, B."Industry-Occupation Mix." Working Paper No. 2012-09, Federal Reserve Bank of San Francisco, September 2012; http://www.frbsf.org/publications/economics/papers/2012/wp12-09bk.pdf. 
Jackman, Richard A.; Layard, Richard and Pissarides, Christopher A. "On Vacancies." Oxford Bulletin of Economics and Statistics, November 1989, 51(4), pp. 377-94.

Jackman, Richard A.; Layard, Richard and Savouri, S. "Mismatch: A Framework for Thought," in Fiorella Padoa-Schioppa, ed., Mismatch and Labour Mobility. Cambridge, UK: Cambridge University Press, 2008, pp. 44-101.

Jackman, Richard A. and Roper, Stephen. "Structural Unemployment." Oxford Bulletin of Economics and Statistics, February 1987, 49(1), pp. 9-36.

Jaimovich, Nir and Siu, Henry E. "The Trend Is the Cycle: Job Polarization and Jobless Recoveries." NBER Working Paper No. 18334, National Bureau of Economic Research, August 2012; http://www.nber.org/papers/w18334.pdf?new window=1.

Lilien, David M. “Sectoral Shifts and Cyclical Unemployment." Journal of Political Economy, August 1982, 90(4), pp. 777-93.

Lucas, Robert E. Jr. and Prescott, Edward C. "Equilibrium Search and Unemployment." Journal of Economic Theory, February 1974, 7(2), pp. 188-209.

Neelin, Janet. "Sectoral Shifts and Canadian Unemployment." Review of Economics and Statistics, November 1987, 69(4), pp. 718-23.

Padoa-Schioppa, Fiorella, ed. Mismatch and Labour Mobility. Cambridge, UK: Cambridge University Press, $2008 \mathrm{.}$

Padoa-Schioppa, Fiorella. "A Cross-country Comparison of Sectoral Mismatch in the 1980s," in Fiorella PadoaSchioppa, ed., Mismatch and Labour Mobility. Cambridge, UK: Cambridge University Press, 2008b, pp. 1-43.

Petrongolo, Barbara and Pissarides, Christopher A. "Looking into the Black Box: A Survey of the Matching Function." Journal of Economic Literature, June 2001, 39(2), pp. 390-431.

Şahin, Ayşegül; Song, Joseph; Topa, Giorgio and Violante, Giovanni L. "Mismatch Unemployment." Staff Report No. 566, Federal Reserve Bank of New York, August 2012; Updated September 2012; http://www.newyorkfed.org/research/economists/sahin/USmismatch.pdf.

Shimer, Robert. "The Cyclical Behavior of Equilibrium Unemployment and Vacancies." American Economic Review, March 2005, 95(1), pp. 25-49.

Shimer, Robert. "Mismatch." American Economic Review, September 2007, 97(4), pp. 1074-101.

U.S. Department of Labor, Bureau of Labor Statistics. "How the Government Measures Unemployment." October 16, 2009; http://www.bls.gov/cps/cps htgm.htm. 
